\title{
Construyendo triángulos para la gestión social del hábitat
}

\section{Esteban de Manuel Jerez*}

\section{Resumen}

Queremos plantear unas herramientas conceptuales que nos permitan mejorar tanto la comprensión de los fenómenos del hábitat como de los procesos encaminados a su producción y gestión social. Para ello nos situamos en la tradición del pensamiento complejo y desde ella integraremos las aportaciones realizadas por teóricos del hábitat social y de la producción social del hábitat. Proponemos una serie de triángulos conceptuales construidos sobre relaciones dialógicas y recursivas entre los elementos que lo componen. Con ellos nos acercamos a la comprensión compleja del hábitat, del hábitat social, de la producción y gestión social del hábitat, y de la función de la universidad en relación con los tópicos anteriores. Por último aplicamos estos conceptos a la interpretación de varios casos en los que hemos participado directamente.

\section{Palabras clave}

Hábitat; Producción social del hábitat; Urbs-Civitas-Polis; Gaia; Participación ciudadana; Complejidad.

\section{Abstract : Constructing triangles for social management of habitat}

We set out some conceptual tools that will improve both the understanding of the phenomena of habitat and the processes leading to its production and social management. To this end, we position ourselves in the tradition of complex thought, and from this point we will integrate the contributions made by theoreticians of the social habitat and of the social production of habitat. We propose a series of conceptual triangles built on dialogical and recursive relationships between the elements of which it is composed. With these triangles, we approach complex understanding of the habitat, of the social habitat, of the social production and management of habitat, and of the role of the university in relation with the aforementioned topics. Lastly, we apply these concepts to the interpretation of various cases in which we participated directly.

\section{Key words}

Habitat; Social Production of Habitat; Urbs-Civitas-Polis; Gaia; Citizen Participation; Complexity.

* Profesor Titular de Universidad. Escuela Técnica Superior de Arquitectura (ETSA), Universidad de Sevilla. Avda. Reina Mercedes, no 2. 41013 Sevilla. E-mail: edemanuel@us.es. 


\section{Hacia una perspectiva compleja del hábitat}

Morin define la complejidad como "el tejido de eventos, acciones, interacciones, retroacciones, determinaciones, azares, que constituyen nuestro mundo fenoménico" (Morin, 1990, p. 35). Frente a la complejidad el pensamiento trata de encontrar elementos de orden y de certidumbre, de quitar ambigüedad, clarificar, distinguir, jerarquizar. Pero, como advierte este autor, tales operaciones corren el riesgo de producir ceguera si eliminan los otros caracteres de lo complejo. El pensamiento complejo aparece allí donde el pensamiento simplificador falla pero integra todo aquello que pone orden, claridad, distinción y precisión en el conocimiento. Aspira a la multidimensionalidad, a la articulación entre dominios disciplinarios quebrados por el pensamiento disgregador.

Existe complejidad cuando hay un tejido interdependiente, interactivo entre las partes y el todo. $Y$ esto ocurre con casi cualquier situación natural y cultural. Morin alerta, de que "los conocimientos divididos no sirven más que para utilizaciones técnicas. No llegan a conjugarse para alimentar un pensamiento que pueda considerar la situación humana, en el seno de la vida, sobre la tierra, en el mundo y que pueda hacer frente a los grandes desafíos de nuestro tiempo. No llegamos a integrar nuestros conocimientos en orden a conducir nuestras vidas" (Morin, 2000, p. 13).

Postula la posibilidad y la necesidad de la unidad de la ciencia: la física, la biología y la antropología. Una unidad no reduccionista, capaz de integrar las alternativas clásicas de unidad-diversidad, azarnecesidad, cantidad-cualidad, sujeto-objeto, holismo-reduccionismo. Una unidad compleja que enlaza el pensamiento analítico-reduccionista y el pensamiento global de modo dialéctico. Para ello es preciso adoptar una perspectiva transdisciplinaria.

Morin propone tres macroconceptos o principios en los que nos vamos a apoyar para aproximarnos al hábitat de forma compleja:

1. El principio dialógico, que nos permite mantener la dualidad en el seno de la unidad. Asocia dos términos a la vez complementarios y antagonistas.

2. El principio de recursividad organizacional. Un proceso recursivo es aquel en el cual los productos y los efectos son, al mismo tiempo, causas y productores de aquello que los produce. La idea recursiva rompe la linealidad causa-efecto, producto-productor, estructura-superestructura, porque todo lo que es producido "reentra" sobre aquello que lo ha producido en un ciclo en sí mismo auto-constitutivo, auto-organizador y auto-productor.

3. El principio hologramático, que establece que no sólo la parte está en el todo, sino que el todo está en la parte. Podemos enriquecer el conocimiento de las partes por el todo y del todo por las partes, en un mismo movimiento productor de conocimientos. Este principio nos permite relacionar un subsistema con un sistema mayor que lo incluye.

Apoyándonos en estos tres principios vamos a construir triángulos relacionales que iremos proponiendo para comprender el hábitat, el hábitat social, la producción social del hábitat y la relación universidad-sociedad-hábitat.

\section{GAIA, el triángulo del hábitat}

El hábitat como sistema complejo está llamado a constituirse en una macrodisciplina o transdisciplina, tanto por la diversidad de disciplinas implicadas en su estudio como por la trascendencia que tiene para el ser humano llegar a gestionarlo con conocimiento y sabiduría. El camino hacia esta construcción transdisciplinaria pasa por establecer relaciones de complementariedad entre disciplinas que centran su atención en cada una de las partes en las que es posible descomponer este objeto de conocimiento. 
Para construir el triángulo de análisis complejo del hábitat nos apoyamos en la "hipótesis Gaia" del biólogo James Lovelock. Este autor nos aporta una perspectiva compleja de la relación entre el medio físico, el biológico y el antropológico. Gaia es el planeta vivo. La vida ha sido posible por unas condiciones físico-químicas de partida, que a su vez han sido modificadas por la aparición de la vida. De modo que la vida desde su aparición ha ido transformando su propio hábitat. A su vez estas transformaciones han propiciado la aparición de formas de vida crecientemente más complejas hasta la aparición del ser humano. El triángulo de GAIA está formado por las interacciones entre el medio físico-químico planetario, los seres vivos que componen la biosfera y el orden antropológico que, como subsistema de la biosfera, introduce una dimensión cultural. Proponemos este triángulo (Figura 1) para el análisis complejo de la relación entre la acción del ser humano, la biosfera y el medio físico planetario.

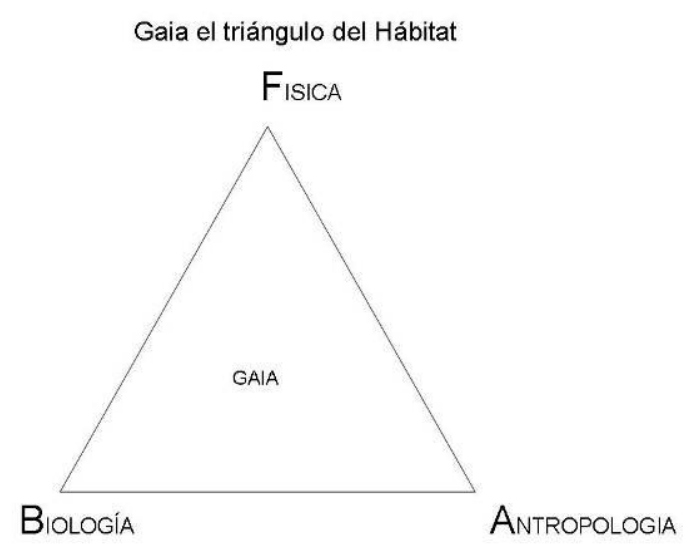

Figura 1: Gaia, el triángulo del hábitat. Fuente: Elaboración propia.

Hoy sabemos que el hombre está produciendo transformaciones de enorme alcance sobre el planeta vivo que afectan a la composición de la atmósfera. El incremento de la proporción de $\mathrm{CO}_{2}$ en la atmósfera está induciendo artificialmente un calentamiento global que a su vez puede ser precursor de una glaciación provocada por la altera- ción de la corriente del Golfo. La acción del hombre sobre el hábitat está destruyendo hábitats naturales de numerosas especies llevándolas a la extinción y poniendo en riesgo amplias zonas habitadas del planeta. Los litorales, los grandes deltas fluviales, archipiélagos enteros del pacífico, se ven amenazados ante la subida del nivel del mar originado por la fusión del hielo de los polos. Están despareciendo en el Himalaya glaciares básicos para el sostenimiento de millones de seres humanos en el Tíbet. Se aprecia un recrudecimiento de fenómenos naturales devastadores como los ciclones y huracanes. Hoy, el nivel de conciencia social que se tiene sobre estos riesgos no se corresponde con las acciones encaminadas a corregirlas, probablemente por esa ceguera que denuncia Edgar Morin (2000 y 2002). La gestión global del hábitat es uno de los retos del siglo XXI y va a precisar conocimiento, voluntad y gestión valiente y eficaz. La cuestión es si seremos capaces de recuperar un equilibrio con la naturaleza. Ello implica necesariamente una drástica disminución de nuestra huella ecológica. Y para ello la ecoeficiencia es condición necesaria pero no suficiente. Es precisa una nueva cultura. La cultura del consumismo es incompatible con un planeta finito. Hoy emerge el concepto de decrecimiento socialmente sostenible para expresar este cambio (Manzano, 2006; Martínez Alier, 2008).

\section{El triángulo del hábitat social: URBS, CIVITAS, POLIS}

Williams Morris nos dejó una definición de arquitectura tan amplia que podemos considerarla como una definición de hábitat que incluye, además, una llamada hacia la necesidad de su gestión social. El hábitat humano se genera por la interacción entre el hombre y el medio para satisfacer sus necesidades de cobijo, de sustento y simbólicas. En su definición está implícita la necesidad de que la sociedad asuma, como en la polis griega, la 
responsabilidad sobre las transformaciones en el hábitat. Podemos considerar en este sentido a Williams Morris un predecesor de los teóricos de la producción social del hábitat y del ecologismo planetario.

La definición más completa y compleja de hábitat social que conocemos la debemos al arquitecto argentino Víctor Pelli. Este investigador entiende el hábitat social como un sistema de situaciones físicas, sociales, económicas, jurídicas, políticas y simbólicas que están interrelacionadas, de forma que un cambio en una de ellas afecta a las demás. Como tal sistema forma parte a su vez de un sistema mayor con el que interacciona. Estas dimensiones del hábitat que propone Pelli podemos agruparlas en las tres dimensiones que propone Horacio Capel, extrapolándolas, y que están en las raíces etimológicas de la ciudad: la URBS, la ClVITAS y la POLIS.

La URBS se refiere a la dimensión física, formal, del hábitat. La arquitectura, el urbanismo, la geografía y la ecología urbana son las disciplinas que se ocupan, fundamentalmente de nuestro medio físico y natural, de la forma de la ciudad y de la ordenación del territorio. La CIVITAS es la raíz de la civilización. Nos remite a la sociedad que da origen a la URBS y que expresa a través de ella su cultura, sus valores, su organización económica. De la civitas se ocupan disciplinas como la historia, la economía, la antropología, la sociología y la filosofía. La POLIS nos remite a la dimensión organizativa y administrativa de la vida en la ciudad y en el territorio, a cómo se toman las decisiones sobre el mismo, a quiénes las toman, cómo se distribuye el poder. Debemos el concepto a los griegos y lo asociamos al nacimiento de la democracia de los ciudadanos, de aquellos que participaban en la asamblea para hacerse responsables de las decisiones sobre los asuntos colectivos. Es el ámbito de la gestión. Para los griegos de la época de Pericles esta tarea era tomada muy en serio hasta el punto de calificar como idiotas a aquellos que se desentendían de la POLIS, de participar en las asambleas para tratar los asuntos colectivos. De su estudio se ocupan disciplinas como el derecho, la politología, la filosofía política y la sociología.

Estas tres dimensiones, de la ciudad que entendemos válidas para el hábitat social, sea rural o urbano, se relacionan entre sí de modo dialógico y recursivo. Son complementarias y cualquier transformación en una de ellas es causa de transformaciones en las otras. Con ellas construimos el triángulo del hábitat social (Figura 2).

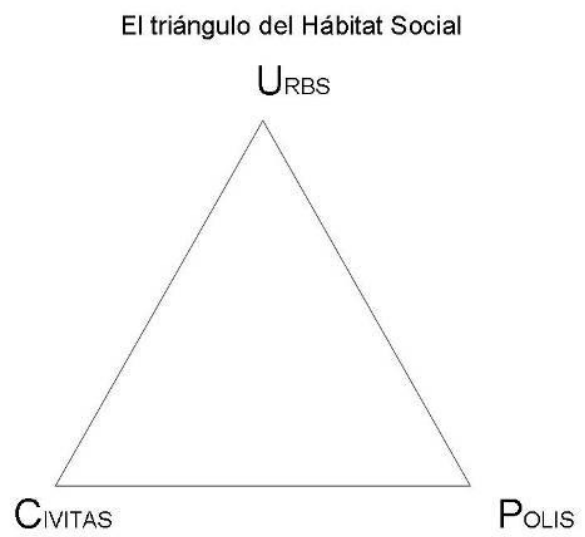

Figura 2: El triángulo del hábitat Social. Fuente: Elaboración propia.

Una transformación de la URBS, de la forma física de los asentamientos humanos y del territorio, puede inducir o ser inducida por un cambio de la CIVITAS. Un cambio en la CIVITAS debido a un incremento poblacional, a un cambio en los modos de vida, en las necesidades sociales sentidas, en los valores, en las dinámicas económicas productivas o de inversión o en las necesidades simbólicas tiene su reflejo en un cambio en la URBS que crece y se transforma para adaptarse a estas necesidades y estos cambios. Pero también tratarán de expresarse mediante nuevas prioridades organizacionales en la POLIS, por conflictos de interés que deberán dilucidarse, por correlaciones de fuerza para conducir los cambios en una u otra dirección y que podrán inducir cambios en el orden 
jurídico que regula las transformaciones en la URBS. Determinadas formas de los asentamientos humanos y de la ordenación del territorio favorecen la aparición de actividades económicas, de oportunidades de interacción social, de mayor auto-organización. Las relaciones entre estos pares de conceptos que articulan este triángulo son claramente recursivas y dialógicas. De modo que quien quiera producir una transformación en el hábitat social puede iniciar la transformación en cualquiera de estas dimensiones e inducir cambios en las otras. Este es uno de los grandes potenciales que tiene la acción sobre el hábitat.

Ahora bien, si hoy tuviéramos que destacar una de estas dimensiones, sin duda nos decantaríamos por la polis. Es preciso reconstruir la polis para recuperar la urbs (De Manuel, 2007). Para ello hace falta que nuestra civitas valorice la responsabilidad de todos hacia nuestro hábitat. Es preciso actualizar la polis griega. Es preciso que todos nos sintamos ciudadanos responsables de la polis, que dediquemos tiempo, conocimiento y acción enérgica al reto de recuperar el equilibrio perdido en la urbs. La polis actual, en los países democráticos, está tecnocratizada. Esto aleja a los ciudadanos de ella y deja el juego de toma de decisiones al arbitrio de promotores inmobiliarios, propietarios del suelo y responsables de las políticas urbanas y de ordenación del territorio. $Y$ en este juego priman los intereses económicos particulares. Es necesaria la participación ciudadana para conseguir que las decisiones que se toman sobre el hábitat se realicen pensando en los intereses de la mayoría de conseguir lugares más habitables, más accesibles, más bellos, más identitarios, más armónicos con la naturaleza, más respetuosos del patrimonio material e inmaterial, menos segregados, más complejos física, funcional y socialmente, más vivos. La participación ciudadana surge hoy como una necesidad. $Y$ es esta participación la que da sentido a la expresión gestión social del hábitat: las decisiones sobre el hábitat son responsabilidad de todos los habitantes. Como decía William Morris, son intereses demasiado vitales como para dejarlos en manos de una minoría.

\section{El triángulo de la producción y gestión del hábitat (polis): Políticos, técnicos y ciudadanos}

"Por producción social del hábitat entendemos todos aquellos procesos generadores de espacios habitables, componentes urbanos y viviendas, que se realizan bajo el control de autoproductores y otros agentes sociales que operan sin fines lucrativos. Parte de la conceptualización de la vivienda y el hábitat como proceso y no como producto terminado; como producto social y cultural y no como mercancía; como acto de habitar y no como mero objeto de intercambio. Se da tanto en el ámbito rural como en el urbano e implica diferentes niveles de participación social en las diversas fases del proceso habitacional: planeación, construcción, distribución, uso" (Ortiz, 2008, p. 31).

A los procesos en los que la sociedad en su conjunto y los usuarios en particular adquieren un rol protagonista en la producción del hábitat les llamamos, siguiendo a Enrique Ortiz, "producción social del hábitat". A nivel mundial la mayor parte de la población es autoproductora de su propio hábitat, con mucha frecuencia, al margen de la regulación del estado y sin asistencia técnica. Lo es por necesidad. El mercado ofrece productos fuera de su alcance económico y el estado no suple estas carencias de forma suficiente. El concepto de producción social del hábitat surge en este contexto y es acuñado por técnicos que se acercan al estudio del fenómeno de la autoproducción de viviendas, tratan de acompañarlos técnicamente y teorizan a partir de estas experiencias. Se implican en el desarrollo de tecnologías constructivas y sociales apropiadas a estos procesos y apropiables por los autoproductores. Así mismo se implican en el análisis crítico de las políticas de hábitat y pos- 
tulan políticas de apoyo a la autoproducción. En nuestro contexto, si bien hemos tenido una gran tradición de autoconstrucción, este fenómeno empieza a ser marginal. Sin embargo emergen iniciativas sociales que reclaman un protagonismo de la sociedad en la toma de decisiones sobre el hábitat, tanto en las políticas urbanas como de vivienda, como en el desarrollo de planes y proyectos. En la medida en que el énfasis se ubica en la toma de decisiones durante el proceso y se reclaman espacios de participación, aplicamos a estos procesos el concepto de gestión social del hábitat. Por Gestión Social del Hábitat entendemos, pues, todos los procesos tendentes a la producción o transformación del hábitat existente en los que la iniciativa social tiene un papel activo en la toma de decisiones.

En la producción y gestión social del hábitat podemos diferenciar tres grupos de actores entre los que podemos encontrar relaciones dialógicas y recursivas (Figura 3).

En primer lugar señalamos a los responsables políticos de la administración pública en los diferentes escalones, desde el ámbito local, regional, estatal o supra estatal. A ellos corresponde aprobar y desarrollar programas de hábitat en sus diferentes escalas: vivienda, urbanismo y ordenación del territorio. Así mismo les corresponde tomar decisiones sobre el modelo de desarrollo económico, políticas sociales y culturales, sobre energía, movilidad y transporte. Son los responsables de velar por el interés público.

En segundo lugar destacamos a los técnicos responsables de asesorar, diseñar y gestionar esos programas y proyectos, al servicio de la administración o de otros actores (promotores privados o iniciativa social).

En tercer lugar destacamos al conjunto de los ciudadanos como usuarios demandantes de necesidades en materia de hábitat, como promotores 0 como autogestores.

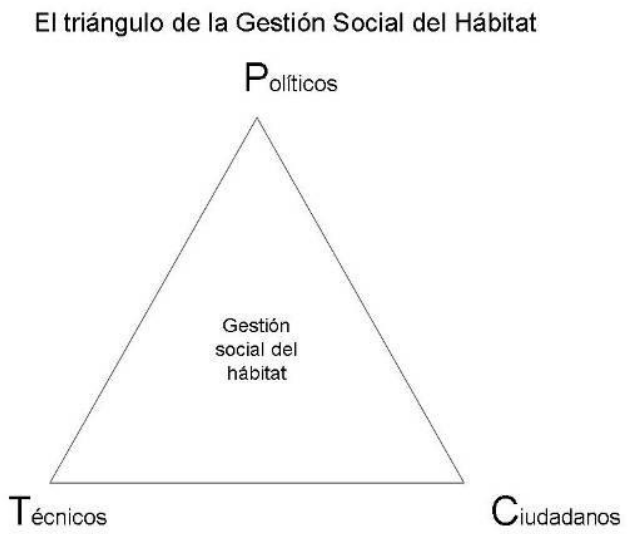

Figura 3: El triángulo de la Gestión Social del Hábitat. Fuente: Elaboración propia.

Las relaciones entre estos tres grupos de actores son frecuentemente conflictivas por defender intereses o perspectivas enfrentados y tratarse de grupos con diferente grado de poder de decisión. En el modelo de producción del hábitat en el que el mercado es protagonista los usuarios pasan a tener condición de meros clientes y usuarios. Las decisiones sobre el modelo de ordenación territorial las toman los gobiernos teniendo como interlocutores principales a los promotores inmobiliarios. Con ellos llegan a acuerdos de clasificación y calificación del suelo que son recogidos en planes y programas. Los técnicos desarrollan y dan forma al hábitat siguiendo las instrucciones de quiénes toman las decisiones.

El modelo de gestión social del hábitat pretende que sea la sociedad en su conjunto quien tome las principales decisiones sobre los modelos de organización de los asentamientos humanos y el territorio. Ello implica un avance hacia formas de democracia participativa en la que se recupere la condición de ciudadanía (Encina et al., 2003). Este modelo pretende crear espacios en los que las decisiones se tomen conjuntamente entre administración, técnicos y ciudadanos de forma equitativa. Políticos, técnicos y ciudadanos están llamados a construir el triángulo equilátero de la gestión social del hábitat, para lo cual han de compartir la voluntad de hacerlo y estar dispuestos a iniciar un pro- 
ceso de aprendizaje, dado que se trata de una innovación que requiere aprender a gestionar la intersectorialidad y la interdisciplinariedad.

De cómo sea la naturaleza de las relaciones que se establecen entre estos actores, así como del rol que juega cada uno de ellos, se desprenden diferentes modelos de gestión social del hábitat, que se corresponden con diferentes formas de pensar y organizar la polis.

En la escala de ordenación del territorio y de planificación urbanística, en las sociedades de mercado, en el triángulo de la gestión del hábitat, en el vértice ciudadano, el papel protagónico lo tienen aquellos que tienen un interés económico directo, en calidad de propietarios del suelo o de promotores inmobiliarios. Sin embargo, existen movimientos sociales que demandan participación en la toma de decisiones sobre el hábitat en sus distintos niveles, desde los que se movilizan para conseguir declarar como protegidos determinados espacios de elevado valor natural o para cambiar el trazado de una gran infraestructura viaria o de transportes, una central de producción energética, o una presa, a quienes demandan poder decidir sobre el modelo urbanístico a escala municipal o de barrio. Estos grupos sociales entran en conflicto con los promotores de aquellas iniciativas sobre el hábitat que consideran lesivas para el medio ambiente o para el interés general. $Y$ con frecuencia se encuentran con que estas iniciativas privadas cuentan con un fuerte respaldo político. Por tanto construir estos triángulos requiere un difícil proceso, y es aún más difícil si desde la administración pública no se tiene el convencimiento de que ello es necesario para mejorar la calidad de la toma de decisiones y su respaldo democrático. El triángulo de la producción y gestión social del hábitat se constituye cuando se crean espacios de participación y concertación entre los diferentes actores, políticos, técnicos y ciudadanos en el proceso de elaboración de un plan o un proyecto de hábitat, de modo que la sociedad adquiere protagonismo real en la toma de decisiones.

En la escala de la producción de vivienda hoy podemos distinguir tres modelos. El primero es el de promoción privada. En este modelo en el vértice ciudadano del triángulo se diferencian dos actores que juegan diferentes roles. De un lado el promotor inmobiliario y de otro el usuario. El promotor adquiere suelo, contrata técnicos que diseñan un plan y/o un proyecto, lo presenta a la aprobación de la administración para obtener las correspondientes autorizaciones y licencias, contrata a una empresa constructora y vende la vivienda como un producto de consumo. El promotor se relaciona de forma dialógica con el usuario demandante de vivienda. Sus intereses son complementarios y antagónicos simultáneamente. El promotor necesita al comprador consumidor y éste a su vez al promotor que le ofrece la vivienda como producto. En este modelo el estado se limita a regular el mercado, establecer las reglas de juego de la promoción de vivienda, conceder ayudas, en su caso a promotores o compradores. Los potenciales demandantes de vivienda por este sistema deben procurarse los recursos financieros necesarios para comprar la vivienda, normalmente mediante crédito hipotecario. La forma de organización social en las sociedades industriales, $y$, en particular, la forma de organizar el reparto de los recursos, deja, como decíamos, a un porcentaje elevado de la población mundial fuera de la posibilidad de acceder a una vivienda promovida por el mercado. Esta dinámica se ha visto enormemente potenciada en las últimas décadas en las que la producción de vivienda se ha orientado más a satisfacer la demanda de objetos de inversión que a la demanda de viviendas para vivir.

Ante esta situación en las sociedades industriales con modelo de estado de bienestar, éste adquiere el rol de promotor público para producir viviendas sociales destinadas a aquellos que por sus ingre- 
sos no pueden acceder a una vivienda de mercado. Surge así la promoción pública de vivienda, muy importante tras la segunda guerra mundial, incluso en regímenes como el franquista, y raquítica a partir de los ochenta, con el predominio de las políticas neoliberales.

Existen varios modelos a través de los cuales el Estado puede jugar el rol de ayuda a los demandantes de viviendas, desde la promoción pública directa a los programas de ayuda para la rehabilitación o la promoción cooperativa de viviendas. Cada uno de estos modelos corresponde a una visión política diferente de la sociedad.

En el modelo de promoción directa es el Estado el que se procura el suelo, contrata a los técnicos y empresas constructoras y establece un sistema por el cual los potenciales demandantes de viviendas pueden llegar a ser adjudicatarios de las mismas. Surgen así los polígonos de vivienda o barridas sociales, normalmente en la periferia de las ciudades, donde el suelo es más barato, segregando a la población de más bajos recursos. El acceso por parte de los ciudadanos a las viviendas públicas puede ser en propiedad o en régimen de alquiler. En el primer caso ha sido frecuente recurrir a la fórmula de venta diferida, con periodos de hasta cincuenta años. Hoy empezamos a percibir los problemas de esta fórmula que hace que barrios enteros pasen a propiedad de personas muy mayores, ya inactivas económicamente, y que han de hacer frente al mantenimiento de edificios que han quedado obsoletos. Ambos modelos de promoción pública tienen en común que asignan un rol pasivo a los usuarios. $Y$ como consecuencia de ello se genera una cultura de dependencia, de asistencia, que pervierte las relaciones entre ciudadanos y administración.

En los modelos de apoyo a la autopromoción o autoconstrucción, el Estado favorece un rol activo de los demandantes de vivienda. La administración puede apoyar al autopromotor de diferentes maneras. El autopromotor, ya sea individual o colectivo, puede acceder a un suelo de titularidad pública, en régimen de cesión de uso o de propiedad, puede conseguir ayudas financieras o subvenciones a fondo perdido y puede obtener apoyo técnico a cargo del estado. El autopromotor contrata ayuda para la construcción o actúa como autoconstructor.

Un tercer rol del estado, que ha sido la vía mayoritariamente empleada en España en las últimas décadas, es la de apoyo al mercado de la vivienda a través de las fórmulas de viviendas protegidas o de precio tasado. Esta vía ha permitido a promotores privados acceder a suelos públicos en condiciones ventajosas para promover y vender viviendas con un precio limitado. Esta fórmula impide a los compradores la venta en el mercado libre en el plazo de 10 años. Pero transcurridos éstos, las viviendas entran de nuevo en el juego del mercado, con lo que el patrimonio público del suelo acaba siendo transferido a manos privadas y facilita procesos especulativos diferidos.

El tercer modelo de producción del hábitat es la autopromoción, que puede incluir o no la autoconstrucción. Si el autopromotor tiene recursos, su rol consiste en sustituir al promotor privado. Promotor y usuario coinciden y entonces el modelo, en lo demás, no difiere, salvo por su escala, del referido para la promoción privada. Si no los tiene, puede acogerse a algún programa público de ayudas.

Cuando las ayudas del Estado no existen o no son suficientes, y el mercado no ofrece viviendas accesibles para una parte mayor o menor de la población, ésta resuelve por sí misma el acceso a la vivienda por sistemas denominados informales por estar al margen del mercado o del estado. El triángulo de actores se reduce a un solo vértice, generalmente. Es la autopromoción y autoconstrucción espontánea, de iniciativa individual u organizada colectivamente, mediante compra de 
suelos baratos, normalmente sin servicios urbanos, o mediante ocupación ilegal del suelo (Salas, 2010). Es un sistema de producción y gestión social del hábitat en el que normalmente no intervienen los técnicos y que puede tener diferentes clases de insuficiencias como solución habitacional. Este modo de producción es mayoritario en grandes áreas de América Latina, África y Asia. Y es el que ha producido casi la mitad de lo construido en Sevilla en el siglo $X X$.

Estos mismos modelos pueden aplicarse en relación con la ordenación del territorio o la ordenación urbana. Podemos encontrar ejemplos de construcción de triángulos equiláteros entre ciudadanos, técnicos y responsables de las políticas públicas en todas las escalas. Pero la escala de barrio parece la más adecuada para la articulación de procesos de participación ciudadana. En un barrio convergen urbs, civitas y polis a una escala humana, donde las relaciones sociales son de proximidad y conocimiento. $Y$ desde esta escala se puede iniciar un debate sobre escalas mayores.

\section{El triángulo de las funciones de la universidad en la producción y gestión social del hábitat}

¿Qué rol puede jugar la universidad en la producción y gestión social del hábitat? La respuesta a la pregunta dependerá del concepto de universidad y de su función social que se tenga. Compartimos con la UNESCO e importantes autores del pensamiento crítico (Morin, 2002; Sousa Santos, 2010; Manzano, en prensa) la perspectiva de que la Universidad está llamada a jugar una función de liderazgo en las transformaciones sociales necesarias para afrontar los retos del presente, entre los que los del hábitat ocupan un lugar relevante. En la tensión en la que se debate la educación entre la función adaptativa y la transformadora, optamos por la segunda, a través de estrategias que rompan el círculo vicioso mediante el cual la educa- ción reproduce la sociedad en la que se inserta su acción en lugar de contribuir a cambiarla. ${ }^{1}$

Estas acciones transformadoras desde la universidad en relación al hábitat y su producción social precisan combinar dos líneas de acción. En primer lugar, la necesaria revolución epistemológica que supone la construcción de un ámbito interdisciplinario y transdisciplinario en torno al hábitat. La universidad tiene que reorganizar el conocimiento, reordenar el pensamiento, para comprender y planificar estrategias de acción en un mundo complejo. Ello implicará una reorganización de las áreas de conocimiento en torno a núcleos organizadores sistémicos como el hábitat y la emergencia de talleres universitarios dedicados a estas problemáticas complejas e interdisciplinares.

$Y$ en segundo lugar requiere una perspectiva también compleja de las funciones de la universidad, para lo cual proponemos la construcción de un triángulo de interacciones entre investigación, educación y extensión universitaria para impulsar su función transformadora. ${ }^{2}$

De esta manera es posible interrelacionar la función de la universidad como formadora de los técnicos y profesionales del hábitat con la función de construcción de conocimiento complejo, transdisciplinario, y la capacidad de hacer ambas cosas insertándose en procesos de producción y gestión

\footnotetext{
1 Hoy la universidad se ve sometida a una presión sobreadaptativa que impulsa a conformar la enseñanza y la investigación a las demandas económicas, técnicas y administrativas del momento. La construcción de la sociedad del conocimiento, entendida en clave economicista, que está detrás de la creación del Espacio Europeo de Educación Superior, presiona a la universidad para incorporarse a la cultura empresarial e impulsar la transferencia de conocimiento hacia las empresas en aras de aumentar su competitividad. Morin utiliza el concepto de recursividad y el de holograma para comprender la compleja relación que se produce entre universidad y sociedad, así como entre cambio estructural y cambio personal, o, en su terminología, reforma del espíritu y reforma de la institución. Frente a esta situación, Morin propugna la acción rompedora de grupos ubicados en los márgenes de la academia como estrategia para romper el círculo vicioso por el cual la educación contribuye a reproducir la sociedad tal y como es en lugar de contribuir a transformarla.

2 Tanto Edgar Morin como la UNESCO coinciden en la necesidad de una revolución epistemólogica, o del pensamiento, que impulse una reorganización de las áreas de conocimiento, hoy excesivamente estancas, en el sentido de construcción de ámbitos de interdisciplinariedad y transdisciplinariedad.
} 
social del hábitat a través de la extensión universitaria (Figura 4).

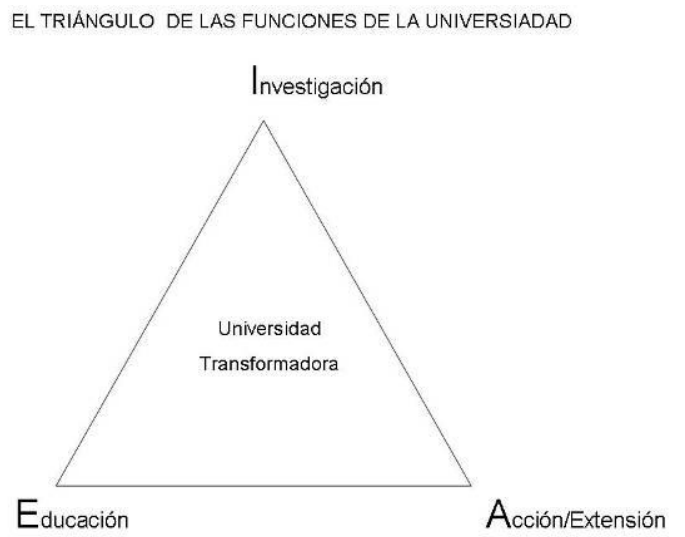

Figura 4: El triángulo de la función transformadora de la Universidad. Fuente: Elaboración propia.

Investigación, Educación y Extensión pueden constituir tres vértices de un triángulo complejo en la medida en que las relaciones entre estas tres funciones son dialógicas y recursivas. De este modo es posible implicar a la universidad como actor relevante en los procesos de estudio e intervención sobre el hábitat. Y es posible hacerlo de forma compleja mediante la interacción de estas tres dimensiones. Ante una misma demanda de asesoría técnica que llegue a la Universidad en relación con una situación de hábitat, ésta puede responder diseñando acciones en las que se construye conocimiento implicando a los técnicos y profesionales en formación, llevando esa demanda de una situación real al aula y tomándola como oportunidad pedagógica, y en el marco de un convenio de colaboración con los actores sociales y las administraciones implicadas en la situación, de modo que se creen espacios de participación para la toma concertada de decisiones sobre la situación de hábitat que ha generado la demanda de asesoría. Esto, desde nuestra experiencia, es posible hacerlo tanto en los cursos de grado como, de forma particularmente intensa, en los de postgrado. De este modo los equipos de profesores y estudiantes implicados, junto con el resto de actores, pueden verse inmersos en procesos en los que simultá- neamente se investiga, se aprende y se transforma una realidad de hábitat.

\section{Las tres grandes olas de cambio sobre el hábitat}

Estos triángulos de análisis necesitan complementarse con una perspectiva temporal. La producción social del hábitat es fundamentalmente de carácter procesual, dinámica, y en el transcurso del tiempo las relaciones que se establecen entre las dimensiones del hábitat y entre los actores van transformándose a medida que se van produciendo acciones e interacciones.

Por otra parte es preciso tener una perspectiva histórica amplia que nos permita entender los grandes procesos globales que han influido en la producción social del hábitat así como anticipar los cambios que son deseables y posibles. Para ello nos resulta muy sugerente utilizar la metáfora que nos propone el sociólogo Alvin Toffler para entender las tres grandes olas de cambio que sintetizan la evolución de la humanidad. Podemos obtener tres imágenes que nos muestran con claridad la evolución en el modo de habitar que cada ola ha introducido. Antes de la primera gran ola de cambio, la que introdujo la agricultura, el hábitat de las sociedades de cazadores recolectores prácticamente no alteraba el entorno natural del que obtenía lo necesario para vivir. Sin embargo ya identificamos unas primeras acciones transformadoras emprendidas por las sociedades humanas para procurarse cobijo, bien aprovechando cuevas, bien construyendo chozas. Unas y otras satisfacían las necesidades de esas sociedades. $Y$ en unas $y$ otras apreciamos ya la introducción de acciones simbólicas: las pinturas rupestres, las decoraciones de las construcciones, por elementales que sean, buscan satisfacer desde muy temprano este tipo de necesidad. Pero la agricultura propicia la aparición de civilización urbana, la construcción de asentamientos en emplazamientos estables que 
irán complejizándose y darán lugar a las ciudades. La agricultura y las ciudades representan un primer salto significativo en el impacto del hábitat humano sobre el medio.

La ciudad es la cuna de la urbs, de la civitas y de la polis. La civilización agrícola nos aporta los fundamentos del urbanismo, del diseño de ciudades, de la civilización sustentada en la escritura y la transmisión, por este medio, del conocimiento, y, con él, de la economía y el comercio, de una creciente complejidad social y cultural, del surgimiento de la historia. $Y$ nos aporta también el surgimiento de la polis, de la organización para decidir en común sobre los asuntos colectivos, dando origen a las tiranías y a la democracia. La civilización agrícola propició una primera red de ciudades, relacionadas por rutas comerciales marítimas y de caminos. El hábitat empieza a adquirir una complejidad y un impacto sobre el territorio cada vez más apreciable. La expresión simbólica empieza a dejar construcciones con una huella perdurable desde las megalíticas a las pirámides y los templos. $Y$ ello empieza a requerir el surgimiento de profesionales especialistas capaces de dar respuesta a necesidades crecientemente complejas. La organización política se expresa a través de las ciudades estado, los imperios, los estados nacionales... Pero durante mucho tiempo la arquitectura será fundamentalmente arquitectura popular. Los arquitectos sólo construyen para el príncipe, la iglesia y los ricos mercaderes. La ciudad de la civilización agrícola es una ciudad compleja desde el punto de vista de las actividades que en ella se producen y de su composición social. Las actividades residenciales, artesanales, comerciales y simbólicas, comparten el espacio. El palacio del noble y el del rico mercader conviven con las viviendas de las clases populares.

La segunda ola de cambio, la introduce la Revolución Industrial. El hábitat humano se transforma desde entonces de forma acelerada y dramática comenzándose un proceso urbanizador desenfrenado con movimientos migratorios del campo a la ciudad (Fernández Durán, 2006). Si a principios del siglo XIX sólo el $3 \%$ de la población mundial vivía en ciudades, a finales del XX la población urbana alcanzaba el 50\%. En este proceso surgen las megaciudades, las metrópolis con millones de habitantes. El cambio es tan rápido que los estados carecen de capacidad para controlar el proceso urbanizador. Surge el urbanismo como ciencia preocupada por resolver los problemas de insalubridad de las ciudades, tugurizadas en sus núcleos históricos y con periferias donde se hacinaban los obreros que requiere la nueva actividad industrial. El urbanismo del movimiento moderno en arquitectura, de base racionalista, preconiza la separación de funciones en la ciudad en lugares para el trabajo, lugares para residir y lugares para el ocio, conectados por redes de infraestructuras. Esto dio lugar a la simplificación de la ciudad, a la segregación funcional (Hall, 1996). Paralelamente se produce la segregación social de la población sobre el territorio en función de su nivel de renta. El siglo $X X$ es el siglo también de la producción masiva de vivienda de iniciativa pública, de los grandes conjuntos residenciales, que tratan de dar respuesta a la demanda de vivienda obrera que no podía ser atendida por el mercado.

A escala planetaria, los países que lideran la industrialización toman el conjunto del planeta como fuente de recursos materiales, de absorción de sus desechos y como mercado para sus productos. La industrialización es posible por la aplicación masiva de las energías fósiles, primero el carbón y luego el petróleo, tanto para la fabricación de productos como para la movilidad de personas y mercancías que se expande exponencialmente. Y la extracción de estos recursos junto con las materias primas que requiere la industria textil y de fabricación de maquinarias y útiles de todo tipo empieza a enfrentar a la humanidad con 
los límites del planeta que le da sustento. La civilización industrial altera el clima, agota los recursos, disminuye drásticamente la superficie forestal, genera enormes desigualdades sociales, produce movimientos poblacionales masivos, y con ellos la aparición del hábitat informal, al margen de planificación, de la acción del mercado y del estado.

La tercera gran ola de cambio la introduce la Revolución de la Información que da inicio a la sociedad del conocimiento. Estamos en transición hacia la misma y es pronto para observar sus implicaciones en el hábitat, detectándose tendencias contradictorias. El acceso a la información y la comunicación favorecen una organización territorial en red descentralizada. Pero, al constituirse como principal materia prima de las actividades económicas más pujantes, está demostrando un enorme poder de acentuación de las desigualdades, con sus plasmaciones territoriales.

Se produce una deslocalización de las industrias de los países centrales hacia la periferia y comienza la transformación de estos paisajes incorporándolos a actividades productivas intensivas en conocimiento, al sector del ocio o residencial. El proceso de globalización económica se caracteriza por situar al sector de inversión financiera al frente de la economía (Stiglitz, 2002; Sampedro, 2002; George, 2010; Morin, 2010; Díaz-Salazar, 2002). Una red de "ciudades mundo" gobierna la economía desde sus citys de Londres, Nueva York, Tokio, Frankfurt... Los núcleos históricos de las ciudades se recuperan y se reciclan como escenarios simbólicos propicios para la industria del turismo cultural produciéndose procesos de gentrificación que expulsan a los sectores populares. El modelo de urbanismo anglosajón se impone, con los barrios residenciales suburbanos y los macrocentros comerciales. La ciudad se hace difusa expandiéndose por el territorio. Las costas de los países cálidos se urbanizan de forma masiva para satisfacer el turismo de masas. El acceso a la información y las comunicaciones desde cualquier punto de la geografía, en los países centrales, posibilita una incipiente recuperación del hábitat rural con un tímido, aún, movimiento inverso de la ciudad hacia el campo por parte de artesanos, artistas, intelectuales, productores de agricultura y ganadería ecológicas...

Estas tres olas de cambio son de onda larga, de modo que hoy vivimos en un mundo en el que persisten pequeñas sociedades de cazadores recolectores, sociedades agrícolas en retroceso, sociedades industriales relocalizándose y emergentes sociedades del conocimiento, con sus respectivas formas de habitar, muchas veces en conflicto. El hábitat de las sociedades cazadoras recolectoras de las selvas tropicales se ve amenazado por las transformaciones introducidas en el hábitat para poner estas selvas en explotación agrícola o ganadera o para extraer sus recursos energéticos y minerales para la sociedad industrial. La sociedad del conocimiento, por su parte, reivindica la conservación de estos enclaves de selva por su función de regulación del clima y mantenimiento de la diversidad genética, materia prima fundamental de las actividades económicas emergentes de la sociedad del conocimiento.

Los conflictos y desigualdades de la sociedad en transición a la sociedad del conocimiento provocan desplazamientos masivos de poblaciones refugiadas y de emigrantes económicos. La libertad de movimiento de capitales que demanda la economía de la sociedad de la información coexiste con limitaciones a la movilidad de mercancías y con fronteras fuertemente protegidas al libre movimiento de personas. Grandes áreas de la geografía mundial parecen haber perdido interés desde el punto de vista de la "economía mundo" y sus poblaciones quedan abandonadas a su suerte. Son tiempos convulsos, de cambio, en los que la polis se muestra débil para conducir el destino de la humanidad. 


\section{¿Qué está pasando con el hábitat?}

Este marco de referencia que proponemos lo venimos utilizando en procesos de reflexión-acción en el aula con los alumnos de grado y postgrado, en materias específicas de hábitat o como transversal en otras, en procesos de educación, construcción de conocimiento y extensión universitaria. En ellos combinamos la inmersión de los alumnos en contextos reales con procesos de producción o transformación social del hábitat en marcha. La perspectiva compleja nos permite relacionar el contexto local con los procesos globales, aprender colaborando con asociaciones vecinales y entidades públicas. Nuestro ámbito geográfico de estudio e intervención se centra en el área metropolitana de Sevilla y en Marruecos, a través de proyectos de cooperación al desarrollo en hábitat. De estas experiencias extraemos sintéticamente algunos casos que hemos tenido oportunidad de estudiar y en los que hemos podido intervenir en diferentes niveles que nos muestran un mosaico de situaciones diversas que nos ilustran sobre qué está ocurriendo con el hábitat. Los narramos, en primera instancia, en un estilo literario, próximo al relato, para facilitar la inserción en el contexto del lector. Posteriormente aplicamos sintéticamente los triángulos analíticos que hemos presentado en la primera parte del artículo.

\section{Bienvenidos a Sunny Hills}

Así reza el cartel publicitario de una malograda promoción urbanística del litoral andaluz. Ubicada en el término municipal de Torrox, entre el núcleo de Torrox Costa y Nerja, unas colinas áridas dominan la larga playa del Peñoncillo, quizá la menos agraciada en varias decenas de kilómetros a la redonda. Desde estas colinas se puede observar la tensión entre el uso agrícola de los llanos y los barrancos y la promoción inmobiliaria del lito-

\footnotetext{
${ }^{3}$ Este relato viene sugerido por el impacto que me produjo pasear este verano, veinte años después, por las colinas del Peñoncillo, cuando empezaba a escribir este artículo.
}

ral. El clima mediterráneo subtropical permite una agricultura singular en Europa, a base de aguacates, chirimoyas, mangos... que, aun retrocediendo ante el avance del Tsunami Urbanizador, se resiste a desaparecer (Figura 5).

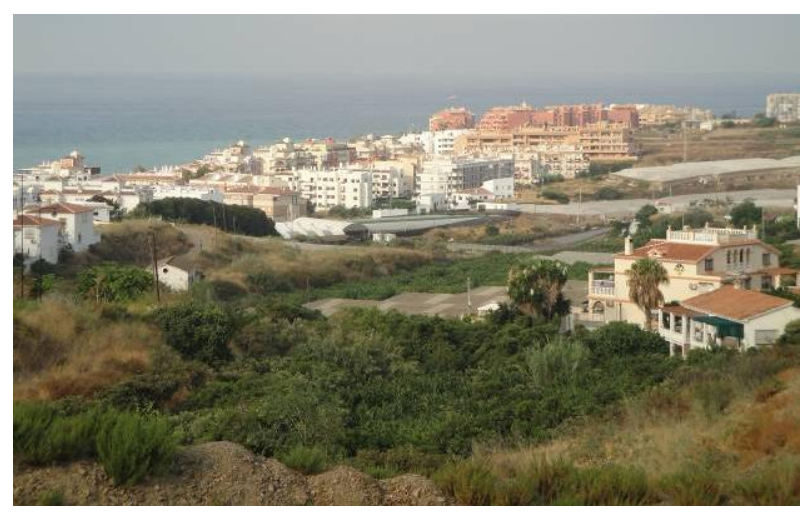

Figura 5: Cultivos subtropicales entre urbanizaciones. Fotografía del autor.

En esta playa, alejada del núcleo turístico municipal, hace treinta años se construyó una urbanización de vivienda colectiva con piscina y pista de tenis, habitada mayoritariamente por turistas alemanes e ingleses. Durante muchos años era el único núcleo urbanizado del Peñoncillo situado en la ladera de una colina. En los últimos años Torrox se ha extendido apoyándose en la carretera paralela a la playa $y$, en vísperas del estallido de la burbuja inmobiliaria, se acometió un vastísimo programa urbanizador de estas colinas.

Sunny Hills está urbanizado y deshabitado. El panorama hoy es desolador: promociones congeladas en plena construcción, el monte convertido en parcelas por vender, algunas casas aisladas que llegaron a construirse y que no se venden, alguna vivienda habitada aislada, muy aislada. Los síntomas de deterioro de la urbanización son evidentes. Un trazado viario mal adaptado a la topografía sufre los efectos de los corrimientos de tierras. Desde los meandros de este viario se divisan caminos peatonales sin paseantes, grúas arrumbadas junto a estructuras sin terminar, barrancos vacíos serpenteados por calles asfaltadas e iluminadas ( $\mathrm{Fi}$ gura 6). 


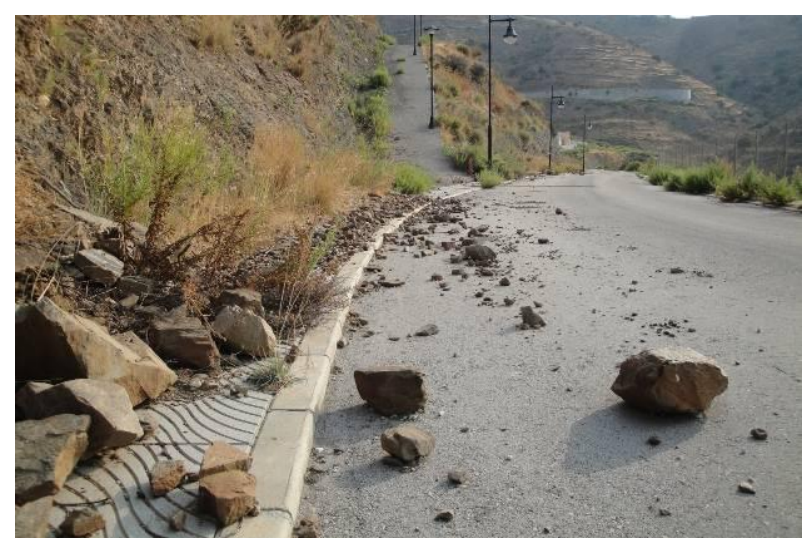

Figura 6: Urbanización sin edificar y en estado abandonado. Fotografía del autor.

El caso de Sunny Hills nos ilustra sobre los efectos del urbanismo salvaje de la última década en España. Casi la mitad de lo que se ha construido en Europa lo ha sido en este país. Todo suelo no parecía tener mejor destino que urbanizarse. Todo lo que se construía se vendía en planos y pasaba de mano en mano. Hasta que se detuvo la música y nos dejó un paisaje de casas vacías con el cartel de (NO) SE VENDE, de urbanizaciones con las calles terminadas para ofrecer parcelas que vender. Despilfarro de recursos materiales, paisajísticos y financieros. Paro masivo. Simultáneamente más de la mitad de las familias españolas encuentran problemas para acceder a una vivienda. La ley de la oferta y la demanda no ha estado dirigida a satisfacer la necesidad de viviendas para vivir. El mercado ha mostrado su ceguera, con la colaboración activa y/o pasiva de técnicos y responsables públicos de urbanismo en todos los niveles de la administración. El stock de más de un millón de casas de reciente promoción sin vender está situado donde no se necesitan para vivir, allí donde las inversiones resultaban más atractivas, en el litoral y en las coronas metropolitanas de las ciudades. Esta CIVITAS de nuevos ricos y adoradores del becerro de oro ha producido una URBS muy simple, monocultivo de viviendas, absolutamente dependientes de los desplazamientos en coche para aprovisionarse en los centros comerciales de lo preciso. El territorio se ha visto invadi- do por una amalgama caótica de urbanizaciones, infraestructuras viarias poco articuladas por las que es difícil orientarse, en las que se suceden promociones clónicas de viviendas, rotondas y centros comerciales. Difícilmente podrán llegar a ser barrios alguna vez, por su excesiva simplificación y segregación de usos, y es casi imposible que aquí emerja una POLIS dada la dificultad de encontrar espacios públicos de convivencia (Figura 7). En ellos es difícil y, cuando menos, aburrido pasear. El triángulo de actores que produce este hábitat está formado por los promotores inmobiliarios, los políticos locales, que ven en este modo de urbanización una forma de financiar sus administraciones locales a corto plazo, y los técnicos de las promotoras privadas $y$ de las administraciones que redactan y aprueban los proyectos. Los ciudadanos quedan reducidos a la categoría de consumidores.

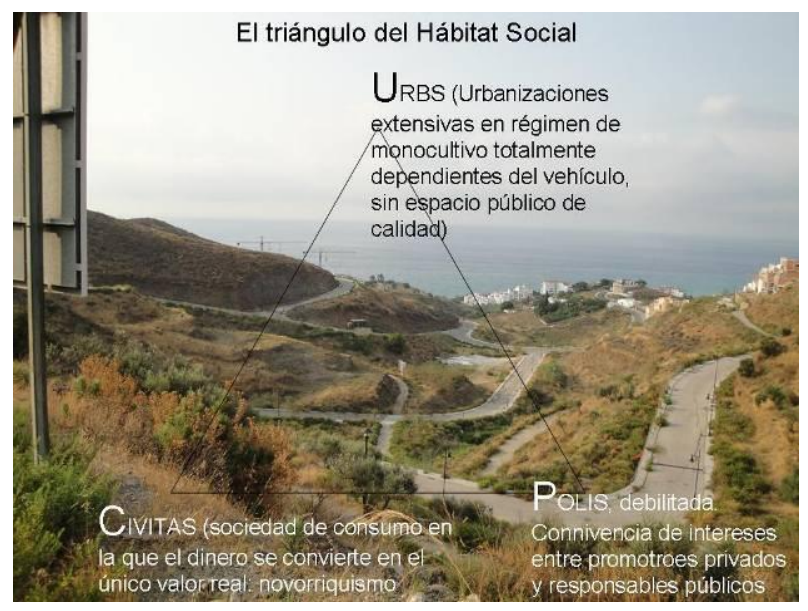

Figura 7: El triángulo del hábitat social de las urbanizaciones extensivas del litoral. Fotografía del autor.

El Informe Auken sobre el impacto de la urbanización extensiva en España en los derechos individuales de los ciudadanos europeos, el medio ambiente y la aplicación del Derecho comunitario pone de manifiesto que esta situación ha sido posible por una cadena de complicidades.

"El gran saqueo material de todos esos años, generador de enormes fortunas y de daños irreparables, no habría sido posible si, paralelamente, no hubiéramos incurrido en el gran saqueo de las 
conciencias al que ahora denominamos 'falta de valores, 'novorriquismo' y cosas semejantes, pero que en los años opulentos, o que creíamos opulentos, estableció una férrea cadena de complicidades entre estafadores y futuros estafados, vinculados unos con otros por el sueño del dinero -sueño, luego, pesadilla para las víctimas- y por la confusión entre bienestar y beneficio" (Argullol,R. 2009)

\section{$\boldsymbol{A h} !$}

Veamos el caso del área metropolitana de Sevilla, que se ha consolidado en las últimas tres décadas sin que haya sido posible aprobar un planeamiento que la organice, pese a que se han redactado planes para la misma en los ochenta y los noventa. ¿Por qué? De nuevo nos enfrentamos a la debilidad de la POLIS. No ha habido voluntad política. Los ayuntamientos se financian fundamentalmente a través del urbanismo, mediante convenios, licencias, etc. Todos los municipios del área metropolitana han competido entre sí por atraer a su término las inversiones urbanizadoras. Para ello toda norma reguladora de rango supramunicipal es un obstáculo. Los alcaldes han tenido más poder que la Consejería de Obras Públicas, responsable de elaborar dicho plan. El resultado es que se ha construido mucha urbanización y poca ciudad.

La URBS resultante es un territorio desestructurado. Una sucesión de urbanizaciones colgadas del viario local preexistente. La CIVITAS rural se ha visto transformada por un aluvión de nuevos habitantes urbanitas que han venido al Aljarafe comprando el sueño de una casa propia adosada, con jardín, a cinco minutos de Sevilla en urbanización con piscina (Figura 8). Los carteles de las promociones venden un arquetipo de casa andaluza con teja árabe. Sobre un fondo de viviendas clónicas un cartel reza: "diferénciate" (si puedes, que añadiría el autor de la foto).

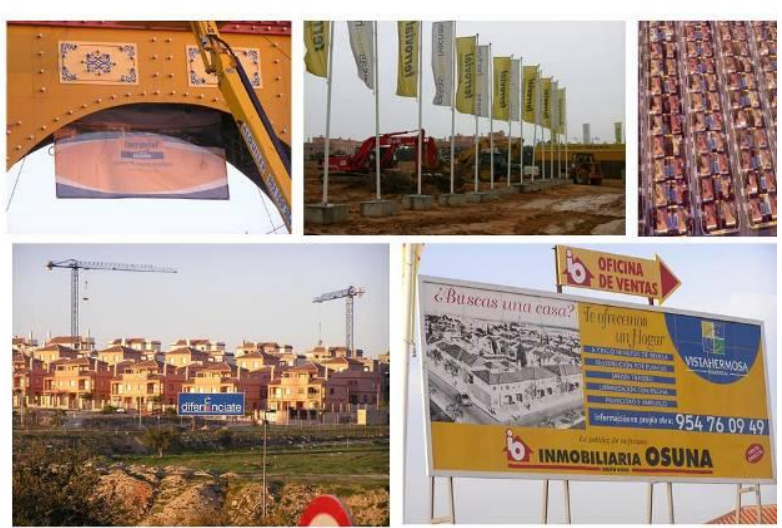

Figura 8: Proceso urbanizador del Aljarafe, en el Área Metropolitana de Sevilla. Fotografías de Luis A. Zambrana.

Estos nuevos habitantes han establecido en general muy pocos vínculos con los pueblos en los que se ubican sus urbanizaciones. Su trabajo está en Sevilla, las compras y el ocio se reparten entre la ciudad y los grandes centros comerciales ubicados en los nudos de las autovías. Buena parte de ellos no se empadronan o tardan en hacerlo, por lo que ni siquiera votan a sus alcaldes. El territorio de las metrópolis se compone de vías con rotondas, urbanizaciones, polígonos industriales y centros comerciales. Es casi imposible recorrerlas a pie o en bicicleta. Las redes de transporte público no han sido previstas. Y la dependencia de una ciudad a la que hay que acceder y de la que hay que salir por tres únicos puentes acaba convirtiendo el sueño en pesadilla: atrapados en los atascos para ir y volver del trabajo (Figura 9).

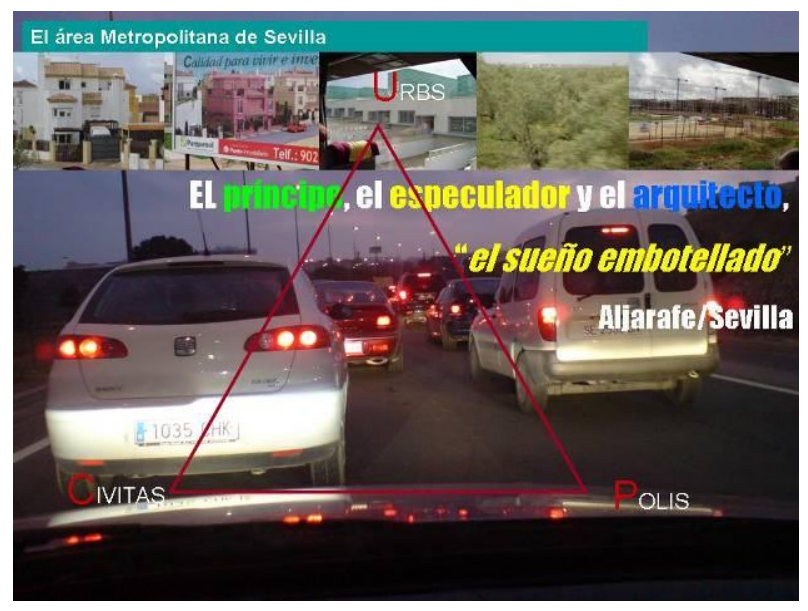

Figura 9: El sueño embotellado. Elaboración propia. Fotografías de Luis Andrés Zambrana y del autor. 
Utilizando el tiempo libre en conducir para aprovisionarse, para llevar a los hijos a las urbanizaciones de sus amigos, a Sevilla, a las actividades extraescolares... al cabo de unos años, se ha visto que este modelo no funciona y empieza a producir el movimiento de retorno a la ciudad por parte de aquellos que pueden.

En este contexto parece difícil que surja una POLIS. Sin embargo, donde hay problemas de hábitat surgen grupos dispuestos a organizarse para afrontarlos. La plataforma Ah! ("Aljarafe habitable") aglutina a activistas que demandan participación ciudadana para poner orden en el territorio. Asociaciones ecologistas y de defensa del patrimonio han tomado la iniciativa para proteger espacios de gran valor paisajístico, como la propia cornisa, proponiendo la creación de un parque arqueológico paisajístico que permita conocer y divulgar los importantes yacimientos dolménicos de los primeros asentamientos humanos sobre estas tierras de Sevilla (Figura 10).

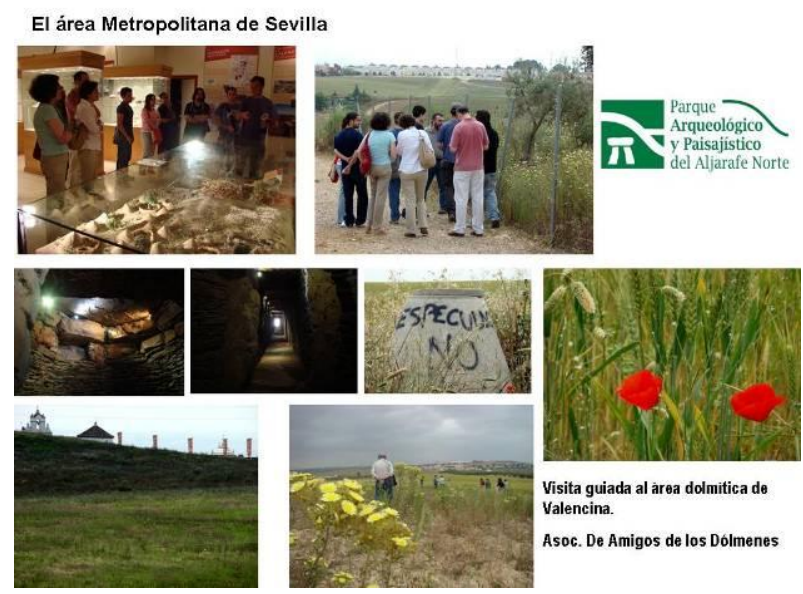

Figura 10: Visita guiada al territorio dolménico donde la iniciativa social promueve el Parque Arqueológico y paisajístico del Aljarafe (Sevilla). Elaboración propia. Fotografías del autor.

Otra iniciativa ciudadana ha promovido la recuperación del cauce del Río Pudio como espacio verde público articulador del Aljarafe. Por su parte la Asociación de Empresarios del Aljarafe, viendo que las disfuncionalidades de este territorio afectan negativamente a las actividades productivas de sus asociados, tras financiar la realización de un informe urbanístico que fue presentado como el libro blanco del Aljarafe, acabó solicitando a la administración una moratoria urbanística. Empresarios, nuevos vecinos que han visto frustrado su sueño de un lugar para vivir, ecologistas, universitarios, han creado una emergente polis ciudadanista antagónica de los intereses especulativos respaldados por las autoridades municipales ante la pasividad de la administración autonómica. En Sanlúcar La Mayor tuvimos la oportunidad de asesorar a un joven equipo de gobierno municipal que había ganado las elecciones tras liderar la oposición a un salvaje plan municipal. Su consigna era hacer un planeamiento sostenible y participativo. En las mesas de participación surgió la propuesta de mantener el carácter rural de este municipio del segundo cinturón del Aljarafe, limitando los desarrollos urbanísticos a lo necesario para el crecimiento vegetativo de la población y para asentar actividades productivas (Figura 11).

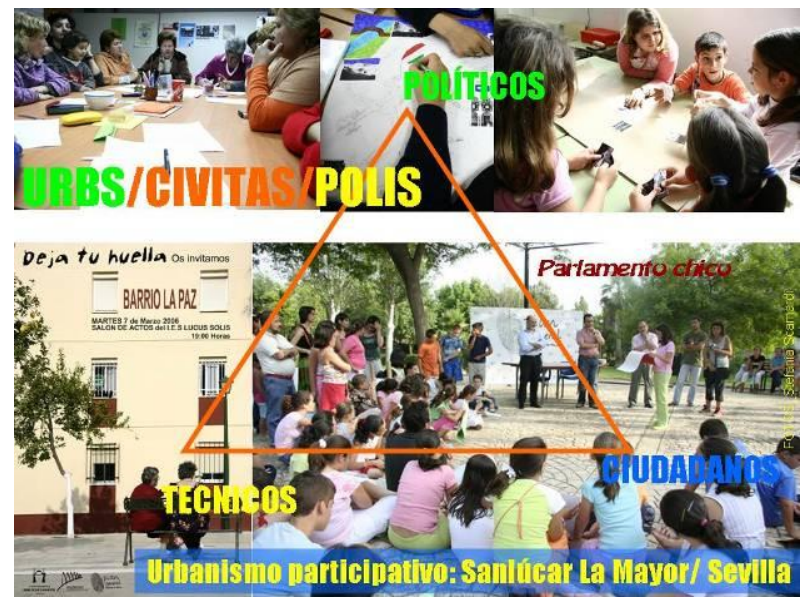

Figura 11: Construcción del triángulo de la gestión social del hábitat en la elaboración del Plan General de Sanlúcar La Mayor (Sevilla). Elaboración propia. Fotografías de Stefania Scamardi.

La crisis ha cogido al Aljarafe con más suelo en promoción, a medio construir o construido vacío del que el mercado de la vivienda, orientado a la inversión financiera, es capaz de absorber. La falta de planificación ha llevado a una superoferta que se ha podido mantener mientras el espejismo especulativo no se ha roto. Hoy ya no es posible. Pero mientras no se haga una lectura autocrítica, por 
parte de las administraciones, de lo ocurrido y de su responsabilidad, difícilmente será posible imaginar un escenario en el que la "nopolis" o "antipolis" actual pueda llegar a ser una ciudad compleja, donde los ciudadanos puedan vivir, trabajar, disfrutar su tiempo de ocio y moverse de forma sostenible, paseando a pie o en bici hasta la parada del transporte público. Para ello habrá que crear espacios de participación y alentar las iniciativas que en esta dirección surjan del movimiento ciudadano.

\section{Urban pa los ricos, desalojo pa los pobres}

Mientras esto ha ocurrido en los suburbios de clase media de las ciudades, los centros históricos se han visto atacados por procesos de gentrificación (Figura 12). Los inversores han comprendido que el valor simbólico de estas áreas les presta grandes oportunidades para obtener beneficios económicos.

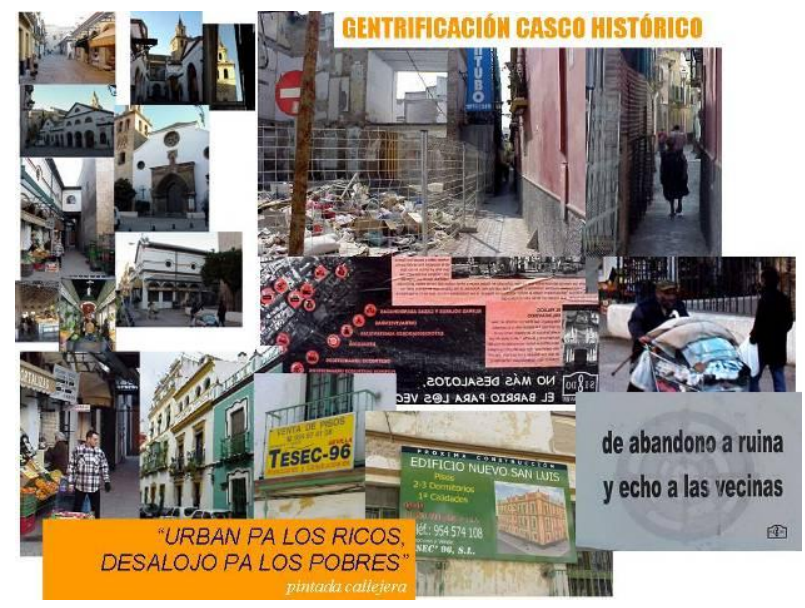

Figura 12: Gentrificación en el Norte del Casco Antiguo de Sevilla. Elaboración propia. Fotografías del autor.

Áreas olvidadas de la ciudad, como el Norte del Casco Antiguo de Sevilla, que en los años noventa fuera escenario de un Plan Urban europeo de recuperación de zonas con necesidad de transformación física y social, han sido escenario privilegiado de estos procesos. La administración pública local, con financiación europea, ha invertido grandes cantidades en remozar la urbs, dotando a las calles de nuevas infraestructuras, repavimen- tándolas, mejorando los espacios públicos. Pero no ha habido la previsión, ni el interés, de hacer un plan municipal de vivienda de forma simultánea. Como trasfondo de estas intervenciones subyacía la errónea idea de que para recuperar la ciudad histórica bastaba con conservar los edificios, o, al menos, la fachada de los edificios. Ello ha dado lugar por doquier a una ciudad museificada donde la mejora de la urbs ha ido de la mano de la desecación de la civitas. Es muy expresiva en este sentido la cita que extraemos de dos antropólogos que han estudiado en su libro La ciudad silenciada el casco antiguo norte de la ciudad:

"El casco antiguo trasunta la historia de una ciudad $\mathrm{y}$, en cierto modo, encierra su especificidad, resume la sociedad que la habita, la cultura que la diferencia. Él conjuga y sintetiza la ciudad toda. Desde nuestro punto de vista, no es tanto su monumentalidad como el tejido social que lo ocupa y le da sentido, lo que le otorga valor; protegerlo implica salvaguardar sus edificios, pero también los espacios y usos sociales que le dan vida." (Cantero, Escalera et al., 1999).

El área de San Luis-Alameda arrojaba al inicio del Plan Urban, en 1994, unas cifras cuantitativamente alarmantes. Casi la mitad de las parcelas estaban ocupadas por edificios en ruina o eran solares. En estas circunstancias, en las que el capital privado inversor no tenía interés por el barrio, hubiera sido fácil y económico conseguir un gran patrimonio municipal de vivienda y suelo.

No se hizo así. De este modo la inversión en espacio público sirvió como llamada al capital privado para entrar en el barrio. $Y$ empezaron a llegar las inmobiliarias y con ellas los "asustaviejas" encargados de hacer realidad su sueño de inmuebles libres de vecinos. "Se compran edificios con vecinos dentro" se podía leer en algunos carteles. La liberalización del alquiler de vivienda decretada por el gobierno nacional, eliminando derechos que protegían a los inquilinos, facilitó la tarea. Aun así se precisaba de una colaboración activa, en mu- 
chas ocasiones, por parte de la administración local, para declarar en ruina las casas de vecinos y proceder a desalojarlas, tal y como ocurrió en la calle Palacios Malaver, donde pude asistir asesorando técnicamente a los vecinos desalojados. Los vecinos acamparon a la puerta de su casa exigiendo soluciones pero perdieron sus derechos.

Donde hay un problema la gente se organiza y reconstruye la POLIS. Este y otros casos hicieron surgir respuestas ciudadanas. Se creó la "Liga de Inquilinos La Corriente" para asesorar, con asistencia técnica, a los vecinos amenazados de desalojo. El barrio, que ya fuera reducto de la resistencia al levantamiento franquista, sigue siendo considerado el barrio rojo de la ciudad. Activistas jóvenes se han unido a los vecinos para salvar la Casa del Pumarejo y crear un centro social autogestionado desde el que presta sus servicios de asesoramiento la Liga La Corriente (Figura 13).

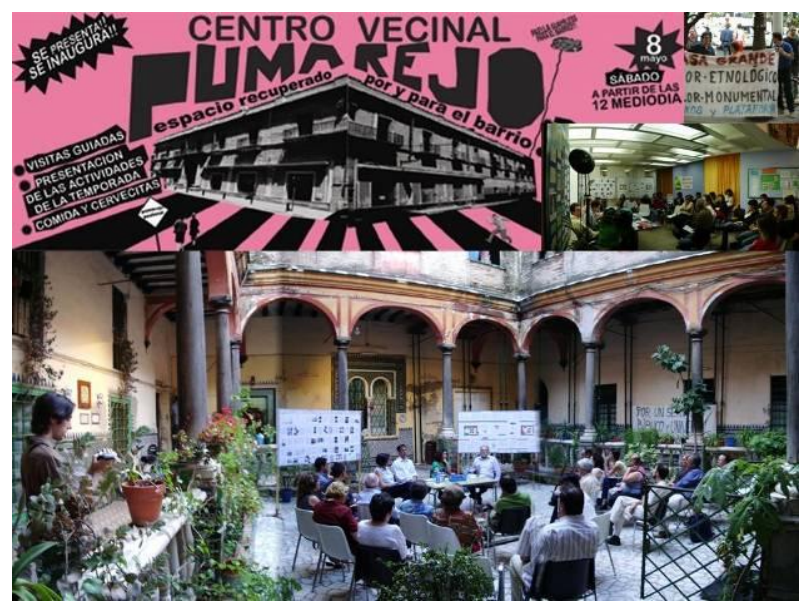

Figura 13: Activismo ciudadano en el Centro Social de la Casa del Pumarejo (Sevilla). Elaboración propia. Fotografías del autor.

Durante más de diez años el barrio ha presenciado acciones de activistas creativos que han organizado "vía crucis" por los edificios del barrio vaciados de vecinos por la especulación. En las fachadas, las estaciones se ilustraban con poesías alusivas. Una pintada callejera expresa cómo es percibido por los vecinos activistas la acción pública: "URBAN PA LOS RICOS, DESALOJO PA LOS
POBRES".

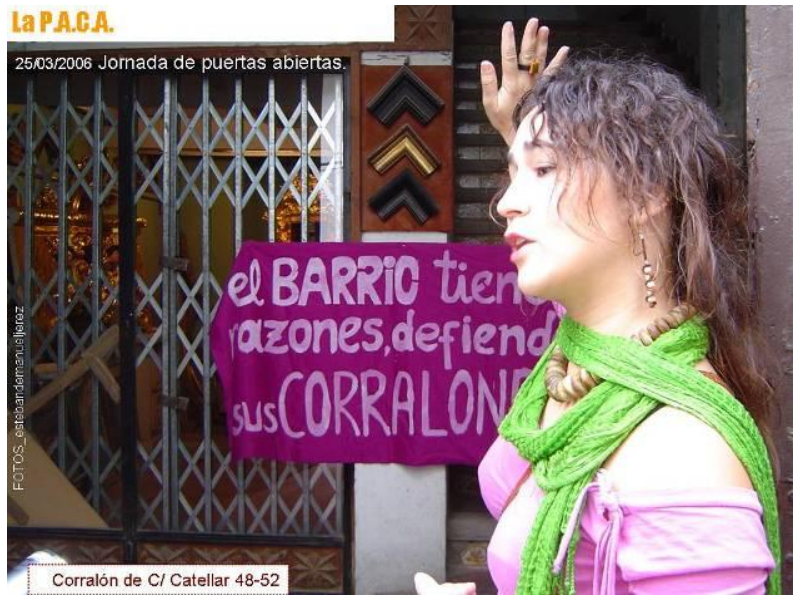

Figura 14: Visita guiada a los corralones artesanales del barrio de San Luis organizada por la Plataforma de Artesanos del Casco Antiguo (Sevilla). Fotografía del autor.

Los artesanos que trabajaban en los corralones del barrio, que han sufrido igualmente las presiones inmobiliarias, se han organizado en la P.A.C.A. (Plataforma de Artesanos del Casco Antiguo) (Figura 14). Desde la Universidad hemos colaborado con esta plataforma a través de la asignatura Hábitat y Desarrollo, construyendo así el triángulo de la función transformadora de la universidad. Los alumnos prepararon un informe para solicitar la declaración de los corralones como Bienes de Interés Cultural Etnográfico, en colaboración con el profesor Javier Hérnandez Ramírez, del Departamento de Antropología Social. Así mismo juntos organizamos una mesa redonda en la Escuela de Arquitectura, en la que construimos un triángulo con los actores implicados en la toma de decisiones sobre el futuro de los artesanos en el barrio. Estuvieron presentes el delegado de urbanismo, el director de la Oficina del Plan de Sevilla, la portavoz de la P.A.C.A. y expertos universitarios en patrimonio industrial. En la mesa se llegó a principios de acuerdo y compromisos políticos para garantizar la continuidad de los corralones artesanales (Figura 15). 


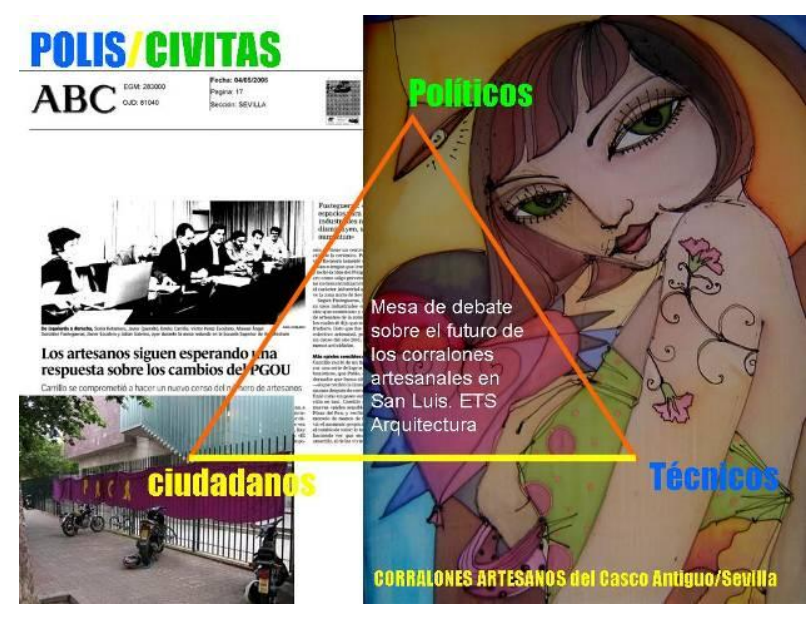

Figura 15: Construcción del triángulo de la Gestión Social del Hábitat y de la Universidad transformadora para apoyar el derecho a permanecer en el centro de los artesanos. Elaboración propia. Fotografías del autor.

Una polis está emergiendo allí donde el mercado está produciendo un cambio en la civitas, desalojando a los vecinos originarios y sustituyéndolos por profesionales, estudiantes que comparten pisos, personas solas o en pareja que ocupan los minúsculos apartamentos que son la oferta dominante. $Y$ estas situaciones de conflicto son propicias para la colaboración entre universidad y movimientos sociales y para que la universidad medie, construyendo un triángulo, con las administraciones públicas responsables. La respuesta de las administraciones local y autonómica al problema de pérdida de población original, y por tanto, de identidad, del barrio, ha venido a través de la declaración de un Área de Rehabilitación Integral que permite diseñar un programa de actuación en el que, mediante acuerdos con los propietarios de inmuebles y ayudas públicas, se está llegando a rehabilitar casas de vecinos con el compromiso de mantener los contratos de alquiler. Es una iniciativa de interés pero que ha tenido escaso éxito por haberse emprendido tarde y en plena burbuja inmobiliaria. Muchos propietarios han encontrado tentadoras ofertas de compra que han considerado más atractivas que el programa. Ante un mercado desaforado la capacidad reguladora de la administración se ha visto muy limitada.

\section{Nosotros También Somos Sevilla}

En los márgenes de la ciudad, allá dónde el mercado inmobiliario carece todavía de intereses, encontramos los llamados polígonos de vivienda social promovidos en la década de los setenta. De esta POLIS, promoción pública directa de carácter sectorial (sólo se actúa desde la política de vivienda) y asistencialista (los demandantes de vivienda juegan un rol pasivo) surge en Sevilla un nuevo tipo de URBS, los Polígonos de Viviendas en la periferia que siguen las directrices de los C.I.A.M. Los mayores son Polígono Norte y Polígono Sur, que han tenido evoluciones bien diferentes. Polígono Sur se ha convertido en un gigantesco gueto, aislado físicamente de la ciudad, donde viven 50.000 personas (Torres, 2005). Se trata de un conglomerado de cinco barriadas de vivienda colectiva en régimen de alquiler o de propiedad diferida. El estado proporcionó viviendas a las clases sociales más necesitadas, procedentes de corrales de vecinos de Triana, San Bernardo, de barriadas de autoconstrucción precarias y de asentamientos chabolistas. Las promociones más deterioradas han sido las de régimen de alquiler público. Se trata de la barriada Martínez Montañés, conocida en la ciudad como "Las Vegas" o, más difusamente, como "Las Tres Mil". Urbanísticamente el barrio responde a los criterios los CIAM, con conjuntos de bloques sobre pilotes y amplios espacios libres. La primera promoción, de 1978, está compuesta por 624 viviendas construidas con pantallas de hormigón y losas prefabricadas para el forjado. Las viviendas resultan amplias y bien distribuidas, para los estándares sociales. Los comercios se debían concentrar en manzanas destinadas a este único fin.

Sin embargo falló la gestión. La administración se desentendió. Nunca se preocupó en las primeras décadas de cobrar el alquiler ni de llevar un registro de los vecinos que realmente ocupaban las viviendas. El impacto en la CIVITAS de esta POLIS 
paternalista, por una parte, y desresponsabilizada, por otro, ha sido demoledor (Figura 16).

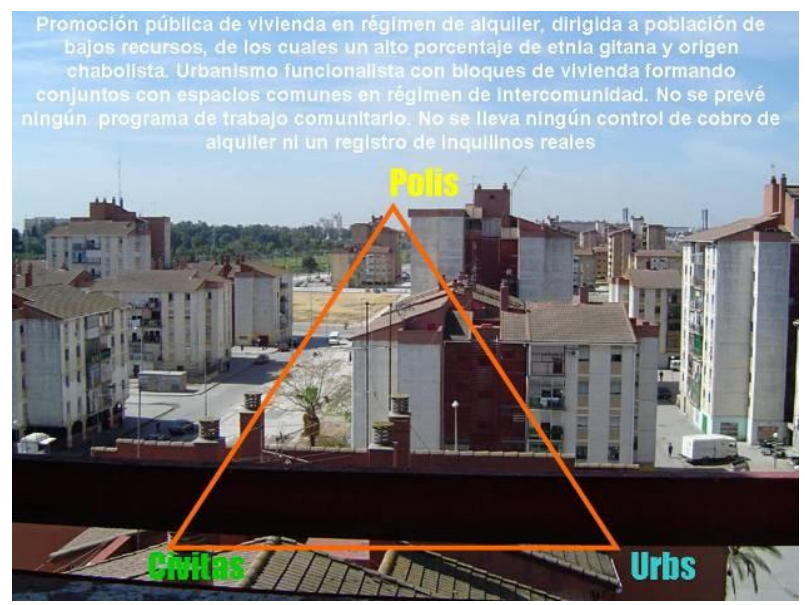

Figura 16: El triángulo del hábitat social en Polígono Sur. Elaboración propia. Fotografía del autor.

El barrio tiene un fuerte porcentaje de población de etnia gitana, con formas de habitar propias, muy apegadas al suelo y a la cultura de la fogata. Ha sido duramente castigado por el paro y la droga en la década de los ochenta. Este detererioro social rápidamente se plasma en el aspecto físico del barrio, la URBS. Los espacios libres se convirtieron en espacios de nadie, inseguros e insalubres. Se produjo un proceso de chabolismo vertical. Empezó el círculo vicioso de la exclusión social (Figura 17).

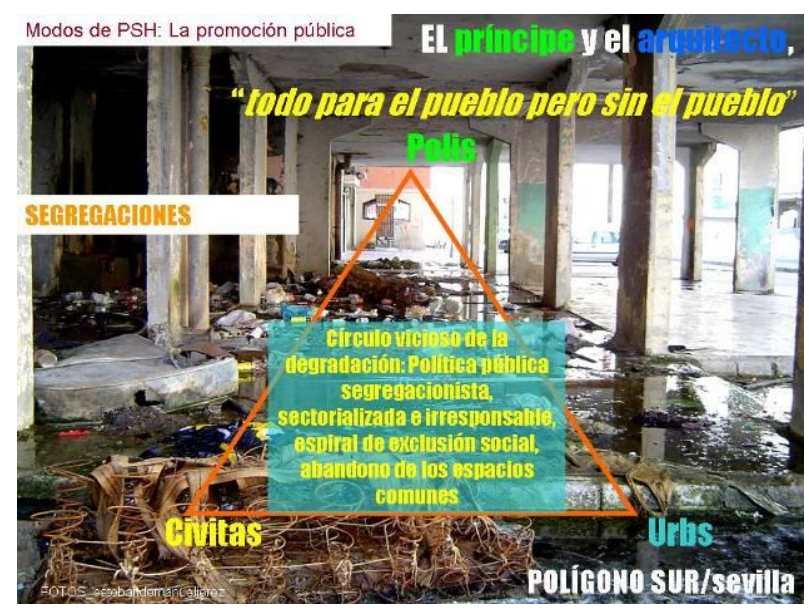

Figura 17: Círculo vicioso del hábitat social en Polígono Sur. Elaboración propia. Fotografía del autor.

El deterioro de la situación social, con altas tasas de desempleo, delinquencia, tráfico y consumo de drogas, absentismo escolar, etc, genera un clima de inseguridad ciudadana. Comienza la construcción del estigma de "Las Tres Mil". Los servicios urbanos empiezan a dejar el barrio. La línea de autobuses urbanos, tras una serie de agresiones a los conductores, decide interrumpir el servicio. Tampoco llega el reparto de correos, la policía, ni el servicio de limpieza pública. Los vecinos han denunciado la situación a través de sus asociaciones. Cuando la situación de deterioro empezó a ser alarmante las distintas administraciones sectoriales emprendieron iniciativas aisladas, de Asuntos Sociales, urbanísticas... con presupuestos elevados que no han dado resultados.

Para romper este círculo vicioso, se rearma la POLIS por iniciativa ciudadana. Las asociaciones vecinales se agrupan en la plataforma vecinal "Nosotros también somos Sevilla" que reclamó una estrategia global de intervención, intersectorial y participativa, con una autoridad única responsable de todas las intervenciones de las diferentes administraciones sectoriales. La situación llegó a alcanzar tal impacto en la opinión pública que se creó en el imaginario político la convicción de que era necesario actuar de forma excepcional ante un problema que se conceptualizaba, erróneamente, como tal.

La Empresa Pública del Suelo de Andalucía recibe el encargo de comenzar las obras de regularización de la tenencia de las viviendas, apoyo e impulso a la creación y funcionamiento de las comunidades vecinales e inicio de las obras de rehabilitación de los edificios. Seguidamente, por acuerdo entre la administración estatal, la autonómica y municipal se constituye la Autoridad Única para el Plan Integral de Polígono Sur, y se nombra a Jesús Maeztu comisionado. Se pone en marcha una oficina técnica para coordinar el plan integral dirigida por Montserrat Rosa que pone en marcha un proceso participativo para el diagnóstico y la redacción del Plan Integral para Polígono Sur, con 
cuatro ejes de intervención: urbanismo y convivencia; salud comunitaria, intervención socioeducativa y familiar, inserción sociolaboral; e iniciativa económica (Comisionado para Polígono Sur, 2004).

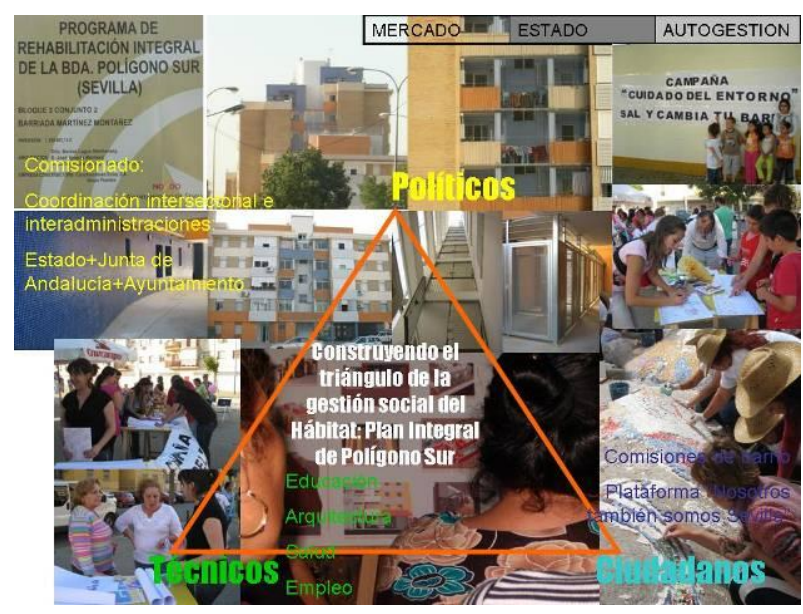

Figura 18: Construcción del triángulo de la Gestión social del Hábitat en el Plan Integral de Polígono Sur. Elaboración propia. Fotografías de S.U.R.C.O. y de los alumnos del Máster en Gestión Social del Hábitat.

Este Plan Integral está construyendo el triángulo de la Gestión Social del Hábitat (Figura 18) creando espacios de participación para los vecinos en diversos escalones: desde la comunidad de usuarios de viviendas en los bloques, la constitución de intercomunidades para gestionar espacios comunes entre bloques y las comisiones de barrio. Así mismo están construyendo espacios de colaboración entre técnicos de las distintas áreas. Juntos, vecinos, técnicos y responsables de la administración han hecho el diagnóstico y el documento de estrategias del Plan Integral. Hoy se está actuando simultáneamente en la rehabilitación de las viviendas (con la consultoría de S.U.R.C.O.), en programas de empleo y activación económica, en educación, salud y acompañamiento social. Hoy la falta de presupuesto, provocada por las presiones financieras del F.M.I. y el Banco Central Europeo sobre el gobierno español, arrojan enormes incertidumbres sobre el final de este proceso que empezaba a ser una referencia internacional de buena práctica sobre el hábitat.

\section{Aprendiendo de Larache: nosotros tam- bién somos medina}

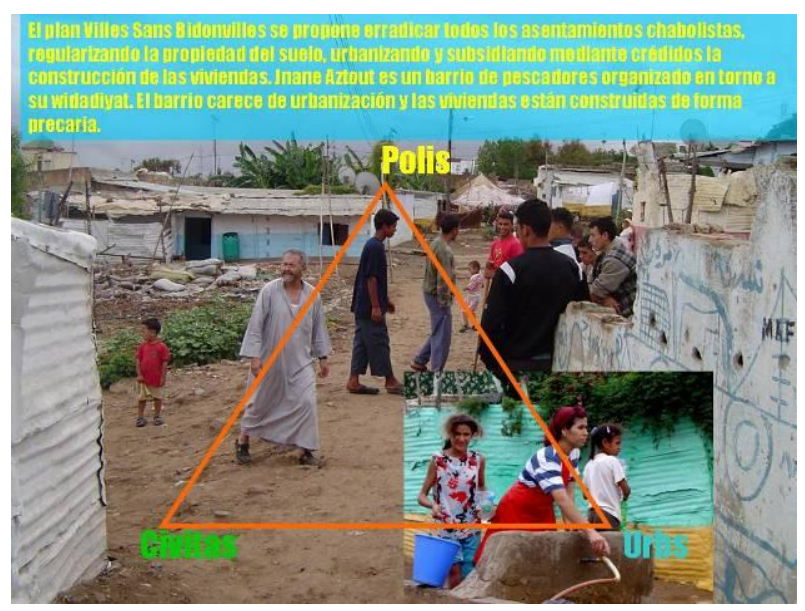

Figura 19: El triángulo del hábitat social en Jnane Aztout, Larache (Marruecos). Elaboración propia. Fotografías del autor.

Mientras tanto, al sur del Estrecho de Gibraltar, en Larache, ciudad de la costa atlántica de Marruecos, en las últimas décadas se está produciendo un intenso proceso de migración desde el campo a la ciudad y desde la ciudad hacia Europa (CIVITAS). Esto ha dado lugar a un cinturón de bidonvilles que rodean las ciudades consolidadas (URBS). El estado marroquí lanzó en 2004 el Plan Villes Sans Bidonvilles con el objetivo de declarar las ciudades libres de chabolas en 2008 (POLIS). Al tiempo, el boom inmobiliario especulativo (CIVITAS) ha llegado a la ciudad, que carece de plan de ordenación urbana (POLIS). Uno de estos bidonvilles, Jnane Aztout (Figura 19), de más de ochenta años de antigüedad, ubicado como un arrabal de la Medina, en la colina que domina el puerto pesquero (URBS), se vio amenazado por estos procesos especulativos (CIVITAS). (De Manuel, 2009; Ojeda y De Manuel, 2009)

En este contexto, por indicación del arquitecto Youssef El Mrabet, asesor marroquí del programa de cooperación de la Consejería de Vivienda de la Junta de Andalucía en Larache, coordinado por el arquitecto Francisco Torres, el grupo de investigación $A D I C I$ y la ONG universitaria Arquitectura y Compromiso Social entran en contacto con los ve- 
cinos del barrio y establecemos un acuerdo de asesoría técnica con dichos vecinos para el diagnóstico de la situación inicial y la elaboración de una estrategia de consolidación urbana y social para el barrio. En este momento, julio de 2005, comienza un proyecto de investigación-acción participativa con implicación docente mediante un proyecto de innovación educativa, a través del Aula de Arquitectura "Arquitectura, ciudad y desarroIlo".

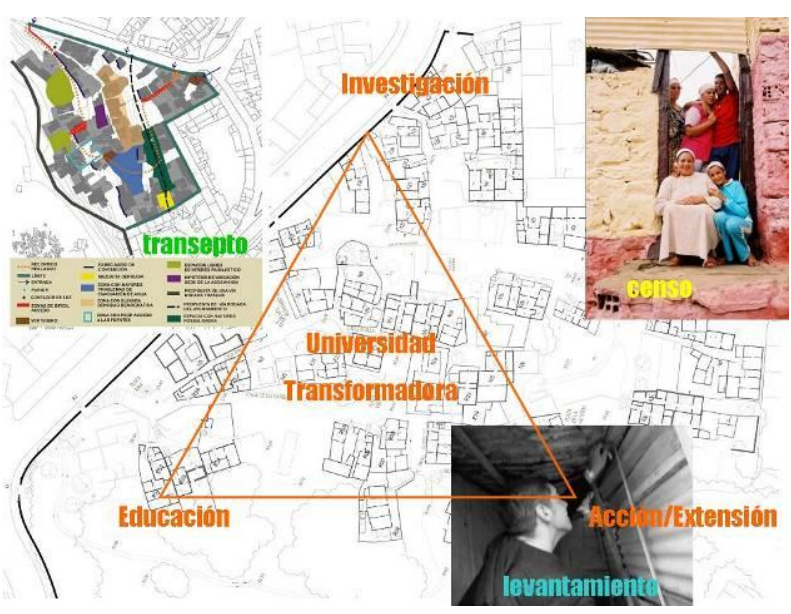

Figura 20: El triángulo de la función transformadora de la universidad en Jnane Aztout, Larache (Marruecos). Elaboración propia. Fotografías de Stefania Scamardi.

De este modo, partiendo de una demanda social, se inicia un proceso que pone en juego el triángulo de la función transformadora de la universidad (Figura 20). Las universidades públicas de Sevilla, a través de dos grupos de investigación, ADICI de arquitectura y GIEST de geografía, y la ONG universitaria Arquitectura y Compromiso Social vienen desarrollando un proyecto integral de investigación, educación y transformación social, en colaboración con la widadiyat del barrio (la asociación vecinal) y la Delegación del Ministerio del Hábitat en Larache. Dicha acción, que se enmarca en el Plan Nacional Villes Sans Bidonvilles y que ha conseguido fondos complementarios de la cooperación española, se planteó como una aseso-ría de acompañamiento técnico y social. En ella se han implicado grupos de profesores y estudiantes del primer curso de arquitectura de Sevilla.

Los estudiantes de este taller integral de arquitectura han realizado levantamientos de todas las viviendas del barrio. El grupo de investigación de geografía realizó un análisis territorial y paisajístico, organizó un censo y el levantamiento de los datos socioeconómicos de las familias. Con toda esta información se elaboró un diagnóstico y una estrategia de intervención en el barrio que apostó por su transformación evolutiva partiendo del derecho de todos los vecinos a permanecer en el barrio.

Los vecinos, pescadores en su mayoría, están plenamente insertados en la ciudad e identificados con el lugar en el que viven y están muy organizados y cohesionados para defender sus derechos. Esta organización más el conocimiento construido conjuntamente sobre su realidad y la estrategia de colaboración consiguiente, más el respaldo institucional de la universidad, permitió a los vecinos que se les reconociera como interlocutores ante las autoridades marroquíes e ir ganando progresivamente el respaldo de sus autoridades a un proyecto que ha sido asumido por éstas como una acción piloto de transformación urbana participativa.

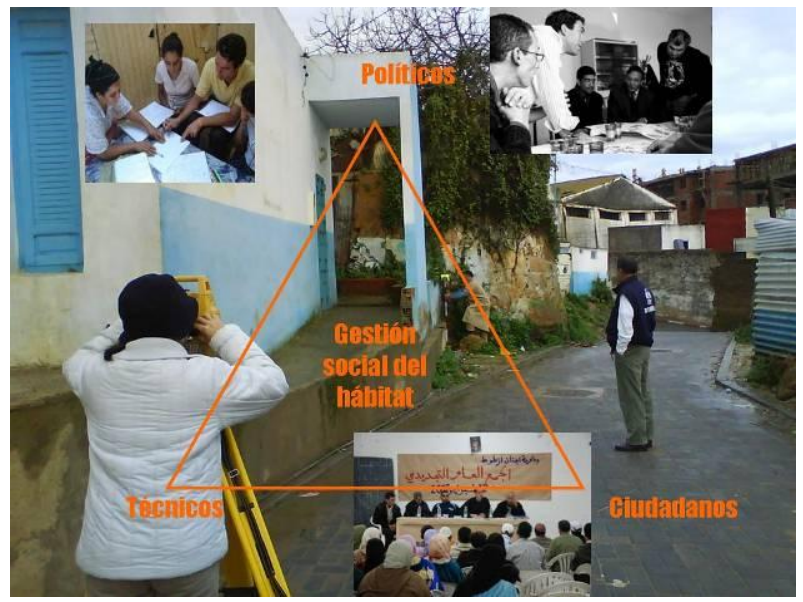

Figura 21: El triángulo de la gestión social del hábitat en Jnane Aztout, Larache (Marruecos). Elaboración propia. Fotografías del autor y Stefania Scamardi.

La clave en este proceso ha sido la construcción del triángulo de la gestión social del hábitat (Figura 
21). Los vecinos, de estar aislados y verse desprotegidos y amenazados han pasado a ser actores sentados en la mesa junto con los técnicos y las autoridades políticas.

Hoy el barrio de chabolas está en pleno proceso de construcción y urbanización. La urbs ha cambiado conservando la sabiduría de la vivienda popular que siempre tuvo el barrio. La civitas, punto fuerte de este barrio en inicio por su rica cultura popular, también se ha transformado. En palabras del presidente de la widadiyat, el objetivo no era sólo acabar con las chabolas como hecho físico. Era preciso eliminar las chabolas de la mente. Y la polis se ha fortalecido. Los vecinos están más organizados y han tomado la iniciativa en la gestión de los temas que quedan pendientes: negociar con la empresa suministradora el abastecimiento de agua al barrio y completar la urbanización del espacio público. Ha sido una experiencia en la que hemos aprendido todos los que en ella hemos participado: estudiantes, profesores, vecinos y responsables de las instituciones marroquíes que lideran el Plan Villes Sans Bidonvilles.

\section{Conclusiones}

Afrontar problemas globales y complejos como los del hábitat requiere una reforma del pensamiento y nuevas estrategias de gestión. Es un tema de conocimiento y de acción, científico y político. Es preciso reconsiderar la relación de la sociedad con su hábitat para llegar a un equilibrio entre natura y cultura. Esto requiere algo más que información, algo más que conocimiento, requiere sabiduría y voluntad firme. El hábitat está llamado a convertirse en un campo de conocimiento transdisciplinario y de acción intersectorial. Y la universidad, como ámbito de construcción de conocimiento y de formación de profesionales del hábitat, tiene en este campo una oportunidad de poner a prueba la interacción de sus funciones en colaboración con los agentes sociales y las administraciones públicas que tienen responsabilidad sobre el mismo.

\section{Referencias}

AUKEN, Margrete. Informe sobre el impacto de la urbanización extensiva en España en los derechos individuales de los ciudadanos europeos, el medio ambiente y la aplicación del derecho comunitario. Bruselas: Parlamento Europeo, 2009. ARGULLOL, Rafael. El gran saqueo. El País, 1205-2009. Madrid.

BARBER, Santiago; FRENSEL, Victoria y ROMERO, MãJosé (Coords.). El Gran Pollo de la Alameda. Sevilla: El Gran Pollo de la Alameda, 2006.

BENEVOLO, Luciano. Introducción a la arquitectura. Barcelona: Gustavo Gili, 1992.

ENET, Mariana. Herramientas para pensar y crear colectivamente en programas intersectoriales de hábitat. Córdoba: CYTED, 2008.

BORJA, Jordi y CASTELLS, Manuel. Local y Global. La Gestión de las ciudades en la era de la información. Madrid, Taurus, 2000.

CANTERO, Pedro; ESCALERA, Javier et al. La ciudad silenciada. Vida social y Plan Urbano en los barrios del Casco Antiguo de Sevilla. Sevilla: Ayuntamiento de Sevilla, 1999.

CAPEL, Horacio. A modo de introducción: los problemas de las ciudades: urbs, civitas y polis. Mediterráneo Económico, 2003, № 3, p. 9-22.

COMISIONADO PARA POLÍGONO SUR. EI Plan Integral de Polígono Sur. Sevilla: Comisionado para Polígono Sur, 2004.

DE MANUEL JEREZ, Esteban. Participar para Recuperar la Polis. In ENCINA, Javier et al. (coords.). La ciudad a escala humana. Sevilla: Ed. Atrapasueños, UNILCO y Universidad y Compromiso Social, 2008, p. 89-102 DE MANUEL JEREZ, Esteban et al. Diseño de procesos educativos globales: Aula SevillaLarache. In Segundas Jornadas de Investigación en Arquitectura y Urbanismo. Barcelona: UPC, 
2006, p. 55-65.

DE MANUEL JEREZ, Esteban. Consolidación Urbana Participativa de Jnane Aztout. In La Ciudad Viva, 2009, no 2. Sevilla: Consejería de Obras Públicas y Vivienda, p. 57-58

DÍAZ-SALAZAR, R. Justicia global. Las alternativas de los movimientos del Foro de Porto Alegre. Barcelona: Icaria, 2002.

ENCINA, Javier et al. Democracias Participativas e Intervención Social Comunitaria desde Andalucía. Sevilla: Ed. Atrapasueños, 2003.

FERNÁNDEZ ALBA, Antonio. La Metrópoli Vacía: aurora y crepúsculo de la arquitectura en la ciudad moderna. Madrid: Antrophos, 1990.

FERNÁNDEZ DURÁN, Ramón: El Tsunami urbanizador español y mundial. Madrid: Virus, 2006.

GEORGE, Susan. Sus crisis, nuestras soluciones. Barcelona: Icaria, 2010.

GONZÁLEZ LOBO, Carlos. Vivienda y ciudad posibles. Bogotá: Escala, 1999.

HALL, Peter: Ciudades del mañana. Historia del urbanismo en el siglo XX. Barcelona: Ediciones del Serbal, 1996.

LÓPEZ MEDINA, José Mª̣; DE MANUEL JEREZ, Esteban et al. Líneas de investigación de A.D.I.C.I.: Diseño de procesos de producción social del hábitat. In Segundas Jornadas de Investigación en Arquitectura y Urbanismo. Barcelona: UPC, 2006, p. 75-85.

LOVELOCK, James. Las Edades de Gaia, Una biografía de nuestro planeta vivo. Barcelona: Tusquets, 1993.

LUCAS, Rafael (Coord.). Polígono Sur. Sevilla: C.O.A.S. / FIDAS, 2008.

MANZANO, Vicente. Energía y sociedad: los debates sobre el agotamiento del petróleo y el "decrecimiento sostenible". CIMA 2006. Madrid, 2006.

MANZANO, Vicente. Universidad Comprometida. Barcelona: Hipatia, en prensa. MARTíNEZ ALIER, Joan (2008). Decrecimiento sostenible: Paris, abril del 2008. Ecología Política, 끄 35 (monográfico sobre Decrecimiento sostenible), p. 51-58.

MORIN, Edgar. Introducción al pensamiento complejo. Barcelona: Gedisa, 1990.

MORIN, Edgar. La mente bien ordenada. Repensar la reformar. Reformar el pensamiento. Barcelona: Seix Barral, 2000.

MORIN, Edgar. Globalización: civilización y barbarie. Diario Clarín, 15-01-2002, p. 16-17. Buenos Aires.

MORIN, Edgar. ¿Hacia el abismo? Globalización en el siglo XXI. Barcelona: Paidós, 2010.

ORTIZ, Enrique. Integración de un sistema de instrumentos de apoyo a la producción social de la vivienda. México: HIC-AL, 2007.

STIGLITZ, Joseph. El malestar en la globalización. Barcelona: Círculo de Lectores, 2002.

OJEDA RIVERA, Juan F. y DE MANUEL JEREZ, Esteban. El riesgo y el placer de aprender. Aprendiendo con Larache. In Proyectos sociales y de cooperación. Transferencia de conocimiento y buenas prácticas. Almería: Háblame Ediciones, 2009, p. 66-69.

OJEDA RIVERA, Juan F. y DE MANUEL JEREZ, Esteban. Una fábrica de sueños: Jnane Aztout. In Proyectos sociales y de cooperación. Transferencia de conocimiento y buenas prácticas. Almería: Háblame Ediciones, 2009, p. 80-85.

PELLI, Víctor S. Habitar, participar, pertenecer, acceder a la vivienda, incluirse en la sociedad. Buenos Aires: Nobuko, 2006.

ROMERO, Gustavo; MESÍAS, Rosendo; ENET, Mariana. La participación en el diseño urbano y arquitectónico en la producción social del hábitat. México: CYTED, 2004.

SALAS, Julián. Mejora de barrios precarios en Latinoamérica: elementos de teoría y práctica. Bogotá: Escala, 2005.

SALAS, Julián (Dir.). Las "tomas" de tierras urbanas en Latinoamérica hoy ¿problema o solución? 
Madrid: Secretaría General Técnica del Ministerio de Vivienda, España, Centro de Publicaciones, 2010.

SAMPEDRO, José Luis. El mercado y la globalización. Barcelona: Círculo de Lectores, 2002.

SOUSA SANTOS, Boaventura de. La Universidad del siglo XXI: Para una reforma democrática y emancipatoria de la universidad. Montevideo: Universidad de la República, 2010.

TOFFLER, Alvin. La Tercera Ola. Barcelona: Plaza y Janés, 1986.

TORRES GUTIÉREZ, Francisco José: El análisis territorial aplicado al estudio de zonas urbanas marginadas: el caso de Polígono Sur en Sevilla. Sevilla: Consejería para la Igualdad y Bienestar
Social, Dirección General de Servicios Sociales e Inclusión, 2005.

UNESCO. Conferencia Mundial sobre Educación

Superior. La educación superior en el siglo XXI: visión y acción. París: UNESCO, 1998.

UNESCO. Hacia las sociedades del conocimiento. París: UNESCO, 2005.

Cita del artículo:

DE MANUEL JEREZ Esteban. Construyendo triángulos para la gestión social del hábitat. Hábitat y Sociedad, 2010, no 1, p. 13-37. <www.habitatysociedad.us.es>.

http://dx.doi.org/10.12795/HabitatySociedad.2010.i1.02 